\title{
Earthquake-induced loss assessment of steel frame buildings with special moment frames designed in highly seismic regions
}

\author{
Seong-Hoon Hwang and Dimitrios G. Lignos*, $\dagger$ \\ Department of Architecture, Civil and Environmental Engineering, École Polytechnique Fédérale de Lausanne (EPFL), \\ Lausanne, Switzerland
}

\begin{abstract}
SUMMARY
This paper discusses an analytical study that quantifies the expected earthquake-induced losses in typical office steel frame buildings designed with perimeter special moment frames in highly seismic regions. It is shown that for seismic events associated with low probabilities of occurrence, losses due to demolition and collapse may be significantly overestimated when the expected loss computations are based on analytical models that ignore the composite beam effects and the interior gravity framing system of a steel frame building. For frequently occurring seismic events building losses are dominated by non-structural content repairs. In this case, the choice of the analytical model representation of the steel frame building becomes less important. Losses due to demolition and collapse in steel frame buildings with special moment frames designed with strong-column/weak-beam ratio larger than 2.0 are reduced by a factor of two compared with those in the same frames designed with a strong-column/weak-beam ratio larger than 1.0 as recommended in ANSI/AISC-341-10. The expected annual losses (EALs) of steel frame buildings with SMFs vary from $0.38 \%$ to $0.74 \%$ over the building life expectancy. The EALs are dominated by repairs of accelerationsensitive non-structural content followed by repairs of drift-sensitive non-structural components. It is found that the effect of strong-column/weak-beam ratio on EALs is negligible. This is not the case when the present value of life-cycle costs is selected as a loss-metric. It is advisable to employ a combination of loss-metrics to assess the earthquake-induced losses in steel frame buildings with special moment frames depending on the seismic performance level of interest. Copyright (c) 2017 John Wiley \& Sons, Ltd.
\end{abstract}

Received 19 October 2015; Revised 24 February 2017; Accepted 24 February 2017

KEY WORDS: loss assessment; expected annual losses; steel special moment frames; losses due to demolition; collapse; life-cycle assessment

\section{INTRODUCTION}

In developed countries with long history in earthquake engineering significant improvements have been made in seismic design provisions for frame buildings [1-3]. This can be seen from the small number of building collapses and the observed seismic performance of new and retrofitted frame buildings in the aftermath of extreme earthquakes $[4,5]$. However, earthquake-induced economic losses in frame buildings because of downtime and business disruption are still a fundamental concern for earthquake-resilient cities. The next generation of performance-based earthquake engineering (PBEE) guidelines [6-8] has incorporated a framework for the reliable seismic performance assessment of frame buildings through collapse. The same framework may be utilized to compute building-specific earthquake-induced losses [9]. This is particularly valuable

\footnotetext{
*Correspondence to: Dimitrios G. Lignos, Department of Architecture, Civil and Environmental Engineering, École Polytechnique Fédérale de Lausanne (EPFL), EPFL ENAC IIC RESSLab, GC B3 485, Station 18, CH-1015 Lausanne, Switzerland

†dimitrios.lignos@epfl.ch 
to stakeholders and building owners such that they can take informed decisions for effective designs and seismic retrofits that minimize such losses in the aftermath of an earthquake.

A number of researchers introduced the first generation of building-specific loss estimation methodologies [10-12] that was later on refined within the Pacific Earthquake Engineering Research center including a number of case studies for reinforced concrete (RC), wood and high-performance structures [13-15]. More recently, Ramirez and Miranda [16] highlighted the influence of residual story drift ratios on earthquake-induced losses in modern RC frame buildings that utilize momentresisting frames (MRFs) as their primary lateral load-resisting system. This may also be a fundamental issue for mid- to high-rise steel frame buildings with MRFs due to their sensitivity to P-Delta effects [17-20]. To this end, it is important to quantify the influence of key seismic design parameters, such as the employed strong-column/weak-beam (SCWB) ratio, on earthquake-induced losses in steel frame buildings with MRFs designed in highly seismic regions.

The application of building-specific loss methodologies into steel frame buildings that experienced past earthquakes has shown that the computed earthquake-induced loss estimates may be overconservative compared with the actual repairs that were done in reality [21]. One possible reason for this may be the fact that typically, numerical models that represent only the bare lateral load-resisting system of a frame building have been utilized to compute engineering demand parameters $(E D P \mathrm{~s})$ that are associated with structural and non-structural damage control $[14,22]$. Other reasons may be related to site effects, as well as the employed component fragility curves $[23,24]$. Such models do not explicitly capture (i) the effects of the composite beam action due to the presence of the floor slab on the lateral stiffness and strength of steel frame buildings under seismic loading [20]; and (ii) the gravity force supported by the gravity framing system that contributes to the destabilizing P-Delta effects [17,25-29]. These are key factors that strongly influence the estimated residual story drift ratios along the height of a steel frame building [30,31]. Therefore, the numerical model representation of a steel frame building may be fairly critical in the computation of its earthquake-induced losses and should be carefully examined.

The purpose of this paper is to quantify the earthquake-induced losses in steel frame buildings with steel special moment frames (SMFs) designed in highly seismic regions such that effective design decisions can be taken prior to the building construction. This is achieved by utilizing a building-specific loss estimation methodology [16] that explicitly considers the effect of residual deformations along the height of frame buildings on the economic loss estimation in the aftermath of an earthquake. The impact of important seismic design variables, such as the SCWB ratio, is quantified on the computed losses. The contribution of the gravity framing system and the composite floor action to the overall building lateral stiffness and strength of steel frame buildings $[20,29,32]$ is considered in this process. This paper provides guidance on the choice of the numerical model representation of steel frame buildings with SMFs to conduct building-specific loss assessment given a selected loss-metric. Three loss-metrics are utilized for this purpose, including the expected losses conditioned on a seismic intensity; the expected annual losses (EALs) that provide information to compare to annual insurance premiums, assuming no deductible; and the present value of life-cycle costs associated with earthquake-induced losses in steel frame buildings with SMFs. The three selected loss-metrics are particularly useful to building owners, stakeholders, (re-)insurance companies in order to take rational decisions for effective designs as well as seismic retrofit strategies to minimize monetary losses in steel frame buildings in the aftermath of an earthquake. It should be stated that losses due to downtime, injuries, and fatalities are not considered in the present paper.

\section{OVERVIEW OF EMPLOYED BUILDING-SPECIFIC LOSS ESTIMATION METHODOLOGY}

The following section summarizes the main aspects of the building-specific loss estimation methodology adopted in this paper as discussed in Ramirez and Miranda [16]. In particular, the possible consequences for a building that experienced an earthquake are as follows: (i) collapse does not occur and structural and/or non-structural components shall be repaired in the aftermath of 
an earthquake; (ii) collapse does not occur, but because of excessive residual deformations along the height of the building it may be demolished and rebuilt; and (iii) collapse occurs and the building shall be rebuilt. Assuming that these consequences are mutually exclusive, the expected value of the loss in the building for a given seismic intensity $I M$ can be defined as follows:

$$
\begin{aligned}
E\left[L_{T} \mid I M\right]= & E\left[L_{T} \mid N C \cap R, I M\right] P(N C \cap R \mid I M)+E\left[L_{T} \mid N C \cap D\right] P(N C \cap D \mid I M) \\
& +E\left[L_{T} \mid C\right] P(C \mid I M)
\end{aligned}
$$

in which $E\left[L_{T} \mid N C \cap R, I M\right]$ is the expected value of the total earthquake-induced loss in the building given that collapse does not occur and the building may be repaired given the occurrence of a seismic intensity $I M=i m ; E\left[L_{T} \mid N C \cap D\right]$ is the expected earthquake-induced loss in the building when there is no collapse but the building may be demolished given the occurrence of a seismic intensity $I M=i m$. In the context of this paper, this loss quantity is assumed to be equal to the total replacement cost of the building plus additional costs due to building demolition and debris removal (normally 10\% of the replacement cost) [33] minus the corresponding cost of those building components that can be recycled (i.e., the $10 \%$ replacement cost); and $E\left[L_{T} \mid C\right]$ is the expected loss in the building when collapse occurs at a given seismic intensity $I M=i m$. This loss corresponds to the total replacement cost of the building. Furthermore, $P(N C \cap R \mid I M)$ is the probability that the building will not collapse but may be repaired or replaced conditioned on the seismic intensity $I M=i m ; P(N C \cap D \mid I M)$ is the probability that the building will not collapse but it may be demolished because of potentially large residual deformations conditioned on the seismic intensity $I M=i m$; and $P(C \mid I M)$ is the probability of collapse conditioned on the seismic intensity $I M=i m$. These probabilities assess the consequences as a function of $E D P$ s used to relate the damage states to building economic losses. Equation (1) can be rewritten as follows:

$$
\begin{aligned}
E\left[L_{T} \mid I M\right]= & E\left[L_{T} \mid N C \cap R, I M\right] P(R \mid N C, I M) P(N C \mid I M) \\
& +E\left[L_{T} \mid N C \cap D\right] P(D \mid N C, I M) P(N C \mid I M)+E\left[L_{T} \mid C\right] P(C \mid I M)
\end{aligned}
$$

in which $P(R \mid N C, I M)$ and $P(N C \mid I M)$ are the probability that the building will be repaired given that no collapse occurred and the probability that the building did not collapse, respectively, given a seismic intensity $I M=i m ; P(D \mid N C, I M)$ is the probability that the building will be demolished given that it has not collapsed when subjected to an earthquake with seismic intensity $I M=i m$. Therefore, Eq. (2) becomes

$$
\begin{aligned}
E\left[L_{T} \mid I M\right]= & E\left[L_{T} \mid N C \cap R, I M\right]\{1-P(D \mid N C, I M)\}\{1-P(C \mid I M)\} \\
& +E\left[L_{T} \mid N C \cap D\right] P(D \mid N C, I M)\{1-P(C \mid I M)\}+E\left[L_{T} \mid C\right] P(C \mid I M)
\end{aligned}
$$

In order to estimate the probability that the building will be demolished given that it has not collapsed when subjected to an earthquake with seismic intensity $I M=i m$, the following relation can be employed:

$$
P(D \mid N C, I M)=\int_{0}^{\infty} P(D \mid R S D R) \mathrm{d} P(R S D R \mid N C, I M)
$$

in which $P(D \mid R S D R)$ is the probability of having to demolish the building conditioned on the maximum residual story drift ratio (RSDR) from all its stories, which is assumed to be a lognormal distribution, defined by a median of 0.015 radians and a logarithmic standard deviation $\beta$ of 0.3 as suggested in [16]. Note that $P(R S D R \mid N C, I M)$ is the probability of exceeding a pre-defined level of RSDR along the height of the building given that it has not collapsed when subjected to an earthquake with seismic intensity $I M=i m$.

\section{DESIGN CHARACTERISTICS OF ARCHETYPE STEEL FRAME BUILDINGS}

A set of archetype steel frame buildings with perimeter SMFs representing offices is utilized such that earthquake-induced economic losses can be quantified. The seismic behavior of these buildings through collapse has been extensively studied in prior analytical studies [20,29,32]. In particular, 
15 steel frame buildings with different number of stories (ranging from 2 to 20 stories) and SCWB ratios (ranging from 1.0, 1.5 and 2.0) are considered. In brief, all the SMFs employ fully restrained beam-to-column connections with reduced beam sections (RBS) designed according to ANSI/AISC 358-10 [34]. The SMFs comply with current seismic provisions in highly seismic regions in North America (i.e., ANSI/AISC 341-10 [3] and ASCE/SEI 7-10 [35]). The steel frame buildings are assumed to be located in the Bulk Mail Center $\left(33.996^{\circ} \mathrm{N}, 118.162^{\circ} \mathrm{W}\right)$ south of Los Angeles, California, which represents a location with high seismicity in urban California [36]. It is assumed that the seismic design category is $D_{\max }$ and that the local site condition is site class $D$ based on a shear wave velocity $v_{s}$ of $259 \mathrm{~m} / \mathrm{s}$. Figure 1 illustrates a plan view and elevation layout of a representative 4-story steel frame building with SMFs. From this figure, the three-bay moment frames are placed along the perimeter of the archetype buildings in a symmetric plan configuration. The interior gravity framing (i.e., floor system and gravity columns) of the 15 steel frame buildings was explicitly designed in accordance with ANSI/AISC 360-10 [37]. The orientation of the strong axis of the interior gravity columns is assumed to be perpendicular to the east-west (E-W) loading direction as shown in Figure 1(a). The gravity column orientation was selected such that we can quantify the contribution of the gravity framing system on the earthquake-induced losses at minimum.

\subsection{Site-specific seismic hazard curves}

The site-specific seismic hazard curves for the 15 steel frame buildings considered as part of this paper are briefly described in this section. These curves are utilized into the $E A L$ computations as discussed in detail in Section 6. The seismic hazard curve data for the 5\% damped first mode spectral acceleration [i.e., $S_{a}\left(T_{1}, 5 \%\right)$ ] are determined from the US Geological Survey website (2010 update of the US national seismic hazard maps). A fourth-order polynomial is fitted to the discrete hazard data points in a log-log scale, which is intended to be used as part of the integration process for the $E A L$ calculations [38]. Figure 2 illustrates the hazard curves for the bare frame numerical models of the 2-, 4-, 8-, 12- and 20-story steel SMFs designed with a SCWB $>1.0$. In this figure, the hazard curves represent the mean annual frequency $\lambda_{S_{a}}$ of exceedance given a spectral acceleration intensity $S_{a}\left(T_{1}, 5 \%\right)$ at the site of interest. The seismic hazard curves shown in Figure 2 vary depending on
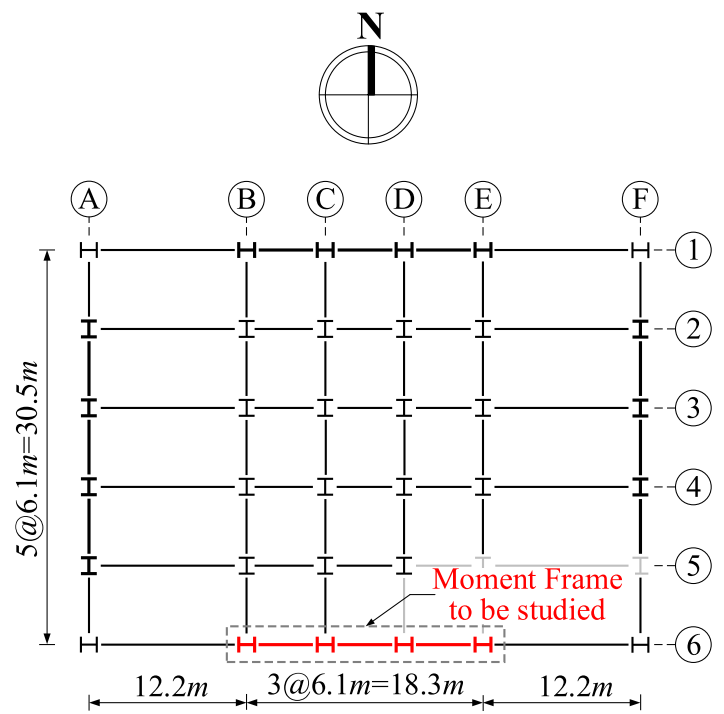

(a)

\begin{tabular}{l|l} 
Note: & $\begin{array}{l}\text { Seismic Design Parameters } \\
\text { Gravity Loads }\end{array}$ \\
Los Angeles, California \\
1. Roof Loading & Risk Category II (office) \\
Dead =4.31 kPa & Importance Factor =1.0 \\
Live $=0.96 \mathrm{kPa}$ & Seismic Design Category $D$ \\
2. Floor Loading & $S_{D S}=1.4 g, S_{D 1}=0.7 g$ \\
Dead = $4.31 \mathrm{kPa}$ & $F_{a}=1.0, F_{v}=1.5$ \\
Live $=2.39 \mathrm{kPa}$ & $R=8, C_{d}=5.5, \Omega_{0}=3.0$
\end{tabular}

(B) (C) (D) E

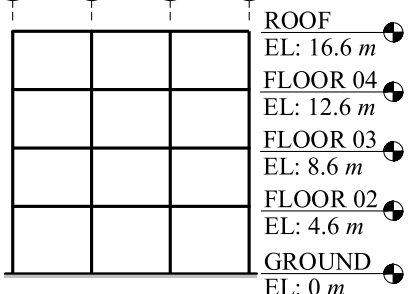

(b)

Figure 1. Typical archetype steel frame buildings: (a) plan view; and (b) elevation of the 4-story special moment frame 


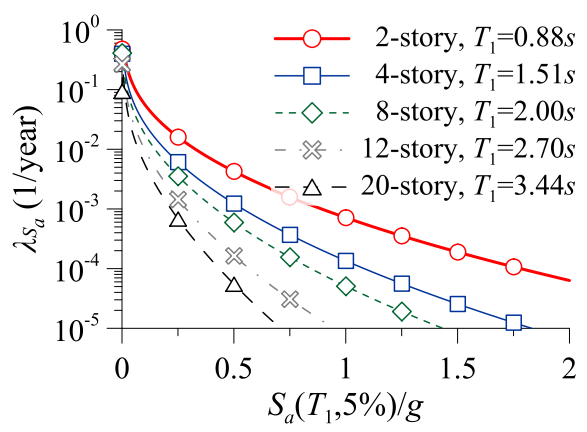

Figure 2. Seismic hazard curves for bare models of all the steel buildings with special moment frames (strong-column/weak-beam $>1.0$ ).

the steel frame building. This is attributed to the fact that these curves depend on the predominant period of the system.

\subsection{Fragility and cost distribution functions}

In order to compute realistic loss estimations for the steel frame buildings being considered architectural layouts were developed. A rectangular footprint that is $1300.65 \mathrm{~m}^{2}\left(14,000 \mathrm{ft}^{2}\right)$ per story is developed [see Figure 1(a)]. The replacement cost estimates for the fifteen buildings that were studied are summarized in Table I. From this table, the base case replacement cost is estimated to be $\$ 2690.97$ per square meter (i.e., $\$ 250$ per square foot) and corresponds to steel buildings with perimeter steel SMFs designed with SCWB $>1.0$. This is a reasonable estimate for steel frame buildings designed in urban California [15]. When a SCWB ratio $>1.5$ and 2.0 is employed as part of the design process of a steel SMF its replacement cost is adjusted according to its total steel weight given that the architectural layout is kept the same in all cases. The total replacement cost estimates are utilized in order to normalize the expected earthquake-induced losses for all the archetype steel frame buildings at various seismic intensities (Sections 5 and 6).

In order to reliably quantify the earthquake-induced losses for the archetype steel frame buildings discussed herein, it is essential to carefully define the fragility distribution curves of their structural and non-structural components. These curves estimate the probability for a component to reach or exceed different damage states as a function of an EDP. Such fragility distribution curves are needed in the estimation of expected earthquake-induced economic losses as discussed in FEMA

Table I. Cost estimates for steel frame buildings studied.

\begin{tabular}{cccc}
\hline Building type & Area $\left(\mathrm{m}^{2}\right)$ & Replacement cost $(\$)$ & Cost per $\mathrm{m}^{2}(\$)$ \\
\hline 2-story SMFs (SCWB $>1.0)$ & 2601 & $7,000,000$ & 2690.98 \\
2-story SMFs (SCWB $>1.5)$ & 2601 & $7,126,000$ & 2739.42 \\
2-story SMFs (SCWB > 2.0) & 2601 & $7,254,268$ & 2788.73 \\
4-story SMFs (SCWB $>1.0)$ & 5203 & $14,000,000$ & 2690.98 \\
4-story SMFs (SCWB > 1.5) & 5203 & $14,252,000$ & 2739.42 \\
4-story SMFs (SCWB > 2.0) & 5203 & $14,508,536$ & 2788.73 \\
8-story SMFs (SCWB > 1.0) & 10,405 & $28,000,000$ & 2690.98 \\
8-story SMFs (SCWB > 1.5) & 10,405 & $28,504,000$ & 2739.42 \\
8-story SMFs (SCWB > 2.0) & 10,405 & $29,017,072$ & 2788.73 \\
12-story SMFs (SCWB > 1.0) & 15,608 & $42,000,000$ & 2690.98 \\
12-story SMFs (SCWB > 1.5) & 15,608 & $42,756,000$ & 2739.42 \\
12-story SMFs (SCWB > 2.0) & 15,608 & $43,525,608$ & 2788.73 \\
20-story SMFs (SCWB > 1.0) & 26,013 & $70,000,000$ & 2690.98 \\
20-story SMFs (SCWB > 1.5) & 26,013 & $71,260,000$ & 2739.42 \\
20-story SMFs (SCWB > 2.0) & 26,013 & $72,542,680$ & 2788.73 \\
\hline
\end{tabular}

SMFs, special moment frames; SCWB, strong-column/weak-beam. 
P-58 [7, 8]. In this paper, the damageable components that are considered as part of a steel frame building are all listed in Table II. It should be stated that out of the total number of non-structural components considered per archetype building, the percentage of the acceleration-sensitive nonstructural components is about the same with that of drift-sensitive non-structural components. Because the archetypes considered in this paper represent modern steel construction in North America, for simplicity it is assumed that the building content that is hanged from the composite floor system, such as mechanical (i.e., the heating, ventilation and air-conditioning systems, HVAC), electrical, plumbing equipment (MEP), as well as stairs including their support, would be properly anchored to the structure; therefore they can be inherently rugged. This assumption is consistent with prior studies related to building-specific earthquake-induced loss assessment [39]. Note that the suspended ceiling is assumed to have both vertical and lateral supports according to the state-of-practice in highly seismic regions (i.e., elements with NISTIR Classification C3032.003d in accordance with FEMA P-58 [7,8]). Table II also summarizes the repair cost per damage state for each component including the respective fragility distribution curve obtained from prior studies $[7,8,39,40]$. Note that the fragility distribution curves are either drift- or acceleration-based depending on the component of interest. An example of the estimated quantities of damageable structural and non-structural components for the 4-story archetype building designed with SCWB $>1.0$ are tabulated in Table III.

It should be stated that the replacement and repair costs of the archetype buildings discussed herein are all computed for a given calendar year (i.e., 2013). Because losses are presented in a normalized manner throughout the paper regardless of the employed loss-metric they are kept consistent. If the computed losses are de-normalized then the inflation should be considered from the time of construction to date. This is consistent with prior studies associated with building-specific loss assessment [7, 14-16,39].

\section{NONLINEAR BUILDING MODELS AND RESPONSE HISTORY ANALYSES THROUGH COLLAPSE}

\subsection{Nonlinear building models}

The Open System for Earthquake Engineering Simulation (OPENSEes) Platform [41] was used to develop 2-dimensional (2-D) nonlinear model representations for all the steel frame buildings in the E-W loading direction [see Figure 1(a)]. It is assumed that a 3-dimensional (3-D) model representation of the archetypes would experience fairly similar structural and non-structural damage with the one predicted from the 2-D model provided that the strong component of the ground motion would be in the same loading direction. This is consistent with findings from a blind analysis contest of a full-scale shake table test of a 4-story steel frame building tested at the E-Defense shake table in Japan [42]. However, this matter deserves more attention and should be examined carefully in future studies. The reason is that depending on the ground motion characteristics, the 3-D movement may cause considerable non-structural damage in the loading direction of the weak-component of the ground motion. In order to investigate the effect of the analytical model representation of a steel frame building on its earthquake-induced economic loss two options are explored: (i) a bare steel SMF model [see the highlighted MRF in the grey dashed box shown in Figure 1(a)], hereafter referred to as $B$-model; and (ii) a model that includes the contributions of the composite beam effects and the interior gravity framing system to the lateral strength and flexural stiffness of the steel frame buildings under consideration as discussed in [20,29], hereafter referred to as $C G$-model.

The SMF steel beams and columns are modeled with elastic elements and concentrated plasticity flexural hinges (i.e., lumped plasticity) at their ends as shown in Figure 3(a). The phenomenological deterioration model that was developed by Ibarra et al. [43] and further refined and calibrated by Lignos and Krawinkler [44], is utilized for this purpose. In order to take into consideration the effect of the composite action on the hysteretic response of steel beams with RBS in $C G$-models the modeling recommendations by Elkady and Lignos [20] are utilized. Figure 3(b) shows a comparison between the deduced beam moment-chord rotation relations as computed with the deterioration 
Table II. Fragility and cost estimates for steel frame buildings with perimeter special moment frames studied.

\begin{tabular}{|c|c|c|c|c|c|c|c|}
\hline \multirow[b]{2}{*}{ Assembly description } & \multirow[b]{2}{*}{ Damage state } & \multirow[b]{2}{*}{ Unit } & \multicolumn{3}{|c|}{$\begin{array}{l}\text { Fragility } \\
\text { parameters }\end{array}$} & \multicolumn{2}{|c|}{$\begin{array}{l}\text { Repair cost } \\
\text { parameters }\end{array}$} \\
\hline & & & $E D P$ & $x_{m}$ & $\beta$ & $x_{m}(\$)$ & $\beta$ \\
\hline \multirow{3}{*}{$\begin{array}{l}\text { Columns base }(\mathrm{W}< \\
223 \mathrm{~kg} / \mathrm{m})[7,8]\end{array}$} & Crack initiation & EA & \multirow{3}{*}{ SDR } & 0.04 & 0.40 & 19,224 & 0.41 \\
\hline & Crack propagation & EA & & 0.07 & 0.40 & 27,263 & 0.37 \\
\hline & Fracture & EA & & 0.10 & 0.40 & 32,423 & 0.34 \\
\hline \multirow{3}{*}{$\begin{array}{l}\text { Columns base } \\
\left(223 \mathrm{~kg} / \mathrm{m}_{i} \mathrm{~W} \leq\right. \\
446 \mathrm{~kg} / \mathrm{m})[7,8]\end{array}$} & Crack initiation & EA & \multirow{3}{*}{ SDR } & 0.04 & 0.40 & 20,082 & 0.39 \\
\hline & Crack propagation & EA & & 0.07 & 0.40 & 29,395 & 0.34 \\
\hline & Fracture & EA & & 0.10 & 0.40 & 36,657 & 0.31 \\
\hline \multirow{3}{*}{$\begin{array}{l}\text { Columns base }(\mathrm{W}> \\
446 \mathrm{~kg} / \mathrm{m})[7,8]\end{array}$} & Crack initiation & EA & \multirow{3}{*}{ SDR } & 0.04 & 0.40 & 21,363 & 0.37 \\
\hline & Crack propagation & EA & & 0.07 & 0.40 & 32,567 & 0.31 \\
\hline & Fracture & EA & & 0.10 & 0.40 & 41,890 & 0.27 \\
\hline \multirow{3}{*}{$\begin{array}{l}\text { Column splices }(\mathrm{W}< \\
223 \mathrm{~kg} / \mathrm{m})[7,8]\end{array}$} & Crack Initiation & EA & \multirow{3}{*}{ SDR } & 0.04 & 0.40 & 9446 & 0.32 \\
\hline & Crack Propagation & EA & & 0.07 & 0.40 & 11,246 & 0.30 \\
\hline & Fracture & EA & & 0.10 & 0.40 & 38,473 & 0.17 \\
\hline \multirow{3}{*}{$\begin{array}{l}\text { Column splices } \\
(223 \mathrm{~kg} / \mathrm{m}<\mathrm{W} \leq \\
446 \mathrm{~kg} / \mathrm{m})[7,8]\end{array}$} & Crack Initiation & EA & \multirow{3}{*}{ SDR } & 0.04 & 0.40 & 10,246 & 0.30 \\
\hline & Crack Propagation & EA & & 0.07 & 0.40 & 13,012 & 0.27 \\
\hline & Fracture & EA & & 0.10 & 0.40 & 42,533 & 0.16 \\
\hline \multirow{3}{*}{$\begin{array}{l}\text { Column splices }(\mathrm{W}> \\
446 \mathrm{~kg} / \mathrm{m})[7,8]\end{array}$} & Crack Initiation & EA & \multirow{3}{*}{ SDR } & 0.04 & 0.40 & 11,446 & 0.27 \\
\hline & Crack Propagation & EA & & 0.07 & 0.40 & 14,812 & 0.24 \\
\hline & Fracture & EA & & 0.10 & 0.40 & 47,594 & 0.14 \\
\hline \multirow{4}{*}{ Column $(\leq \mathrm{W} 27)[7,8]$} & LB & EA & & 0.03 & 0.30 & 16,033 & 0.35 \\
\hline & LTB & EA & SDR & 0.04 & 0.30 & 25,933 & 0.31 \\
\hline & Fracture & EA & & 0.05 & 0.30 & 25,933 & 0.31 \\
\hline & LB & EA & & 0.03 & 0.30 & 17,033 & 0.33 \\
\hline Column $(\geq$ W30) $[7,8]$ & LTB & EA & SDR & 0.04 & 0.30 & 28,433 & 0.28 \\
\hline & Fracture & EA & & 0.05 & 0.30 & 28,433 & 0.28 \\
\hline RBS connections & Yielding & EA & & 0.01 & 0.17 & 0 & 0 \\
\hline (one-sided, $\leq$ & LB & EA & SDR & 0.0216 & 0.30 & 16,033 & 0.35 \\
\hline W27) [40] & Fracture & EA & & 0.05 & 0.30 & 25,933 & 0.31 \\
\hline RBS connections & Yielding & EA & & 0.01 & 0.17 & 0 & 0 \\
\hline (one-sided, $\geq$ & LB & EA & SDR & 0.0216 & 0.30 & 17,033 & 0.33 \\
\hline W30) [40] & Fracture & EA & & 0.05 & 0.30 & 28,433 & 0.28 \\
\hline RBS connections & Yielding & EA & & 0.01 & 0.17 & 0 & 0 \\
\hline (two-sided, $\leq$ & LB & EA & SDR & 0.0216 & 0.30 & 26,567 & 0.33 \\
\hline W27) [40] & Fracture & EA & & 0.05 & 0.30 & 46,999 & 0.28 \\
\hline RBS connections & Yielding & EA & & 0.01 & 0.17 & 0 & 0 \\
\hline (one-sided, $\geq$ & LB & EA & SDR & 0.0216 & 0.30 & 28,733 & 0.31 \\
\hline W30) [40] & Fracture & EA & & 0.05 & 0.30 & 52,399 & 0.25 \\
\hline & Yielding & EA & & 0.04 & 0.40 & 12,107 & 0.37 \\
\hline Shear tab & Partial tearing & EA & SDR & 0.08 & 0.40 & 12,357 & 0.38 \\
\hline & Complete separation & EA & & 0.11 & 0.40 & 12,307 & 0.38 \\
\hline Corrugated Slab & Crack initiation & $m^{2}$ & & 0.00375 & 0.13 & 180 & 0.35 \\
\hline$(90 \mathrm{~mm}$ steel; $100 \mathrm{~mm}$ & Crushing near column & $\mathrm{m}^{2}$ & SDR & 0.01 & 0.22 & 330 & 0.35 \\
\hline overlay) [23] & Shear stud fracture & $\mathrm{m}^{2}$ & & 0.05 & 0.35 & 570 & 0.35 \\
\hline Drywall nartition [30] & Visible & $5.95 \mathrm{~m}^{2}$ & SDR & 0.0039 & 0.17 & 90 & 0.20 \\
\hline Drywall partition [39] & Significant & $5.95 \mathrm{~m}^{2}$ & SDK & 0.0085 & 0.23 & 530 & 0.20 \\
\hline & Visible & $5.95 \mathrm{~m}^{2}$ & SDR & 0.0039 & 0.17 & 90 & 0.20 \\
\hline Drywall finish $[3$ & Significant & $5.95 \mathrm{~m}^{2}$ & SDR & 0.0085 & 0.23 & 250 & 0.20 \\
\hline & Crack & pane & & 0.04 & 0.36 & 440 & 0.26 \\
\hline & Fallout & pane & SDR & 0.046 & 0.33 & 440 & 0.26 \\
\hline & $5 \%$ tiles dislodge & $232.26 \mathrm{~m}^{2}$ & & 0.35 & 0.4 & 3542 & 0.55 \\
\hline$\left(A>23226 \mathrm{~m}^{2}\right)$ & $30 \%$ tiles dislodge & $232.26 \mathrm{~m}^{2}$ & PFA $(g)$ & 0.55 & 0.4 & 29,337 & 0.50 \\
\hline$\left(A>232.26 m^{-}\right)[1,8]$ & Collapse & $232.26 \mathrm{~m}^{2}$ & & 0.8 & 0.4 & 55,199 & 0.20 \\
\hline $\begin{array}{l}\text { Automatic sprinklers } \\
\text { [39] }\end{array}$ & Fracture & $3.66 \mathrm{~m}$ & PFA $(g)$ & 0.32 & 1.40 & 900 & 0.50 \\
\hline Elevator $[7,8]$ & Failure & EA & PGA $(g)$ & 0.50 & 0.28 & 868 & 0.82 \\
\hline
\end{tabular}

$E D P$, engineering demand parameter; LB, local buckling; LTB, lateral-torsional buckling; RBS, reduced beam sections; SDR, story drift ratio (unitless); PFA, peak floor absolute acceleration $(g)$; PGA, peak ground acceleration $(g) ; \beta$, lognormal standard deviation. 
Table III. Example of damageable components for the 4-story steel frame building with perimeter SMFs designed with SCWB $>1.0$.

\begin{tabular}{ccc}
\hline Assembly description & Unit & Quantity \\
\hline Column base plates $(\mathrm{W}<223 \mathrm{~kg} / \mathrm{m})$ & EA & 16 \\
Column splices $(\mathrm{W}<223 \mathrm{~kg} / \mathrm{m})$ & EA & 36 \\
Column $(\leq \mathrm{W} 27)$ & EA & 144 \\
RBS connections (one-sided, $\leq \mathrm{W} 27)$ & EA & 32 \\
RBS connections (two-sided, $\leq \mathrm{W} 27)$ & EA & 32 \\
Shear tab connections & EA & 384 \\
Corrugated Slab (90mm steel; $100 \mathrm{~mm}$ overlay) & $\mathrm{m}^{2}$ & 5203 \\
Drywall partition & $5.95 \mathrm{~m}^{2}$ & 854 \\
Drywall finish & $5.95 \mathrm{~m}^{2}$ & 854 \\
Exterior glazing & pane & 864 \\
Automatic sprinklers & $232.26 \mathrm{~m}^{2}$ & 23 \\
Elevator & $3.66 m$ & 514 \\
\hline
\end{tabular}

RBS, reduced beam sections; SMFs, special moment frames; SCWB, strong-column/weak-beam.

model and as measured from full-scale experiments [45]. To represent the hysteretic behavior of a beam-to-column joint panel zone, a parallelogram model is used as discussed in [17]. Second order effects (i.e., P-Delta) are included in both $B$ - and $C G$-models simulated with a fictitious 'leaning column' and an 'equivalent gravity frame' [see Figure 3(a)], respectively, connected with the steel SMF through axially rigid links. For each story, the flexural strength and stiffness properties of the columns as part of the 'equivalent gravity frame' are equal to half of the summation of those of the interior gravity framing plus those from the SMFs in the orthogonal (i.e., north-south) loading direction. Similarly, the equivalent gravity beams per floor are assigned a flexural strength and stiffness equal to half of the summation of those of the gravity beams in the E-W loading direction as discussed in Gupta and Krawinkler [17] and Elkady and Lignos [29].

For the $C G$-models the gravity framing is considered as discussed in Elkady and Lignos [29]. This requires a realistic representation of single-plate shear tab beam-to-column connections that are used in the design of a typical floor system of a steel frame building per ANSI/AISC 360-10 [37]. Figure 3(c) illustrates a comparison of the measured and simulated moment-chord rotation hysteretic relations of a composite beam as part of a single-plate shear tab beam-to-column connection including the possibility of beam binding on the column flange [29]. From Figures 3(b) and (c), the employed modeling approaches for steel beams in composite beam-to-column moment connections are found to be in reasonable agreement with the experimental results from full-scale tests.

Damping is simulated with the Rayleigh model. Two percent damping ratio $(\zeta=2 \%)$ is assigned to the first and third modes of all the model representations of the archetype buildings. In order to avoid issues related to artificial damping forces, the modeling approach discussed in Zareian and Medina [47] is employed for modeling damping with the Rayleigh model.

\subsection{Collapse simulations}

The analytical model representations of the archetype buildings discussed in Section 4.1 are subjected to the Far-Field set of 44 ground motions documented in FEMA P695 [48]. These ground motions are representative of the seismic hazard of the design location. In order to estimate the seismic demands of the archetype buildings from the onset of damage through collapse due to sidesway instability [42,49-51], the ground motion records are scaled incrementally as discussed in Vamvatsikos and Cornell [52] (i.e., incremental dynamic analysis, IDA). The 5\% damped first mode spectral acceleration, $S_{a}\left(T_{1}, 5 \%\right)$ of each numerical model representation is used as an $I M$. The ground motions are scaled incrementally till a story or a number of stories displaces sufficiently and the first order story shear resistance becomes zero (i.e., dynamic instability occurs). Because the emphasis of the paper is not on ground motion selection and scaling, the same ground motions are scaled at all intensities without setting a limit on the amount of scaling. Often times, the use 


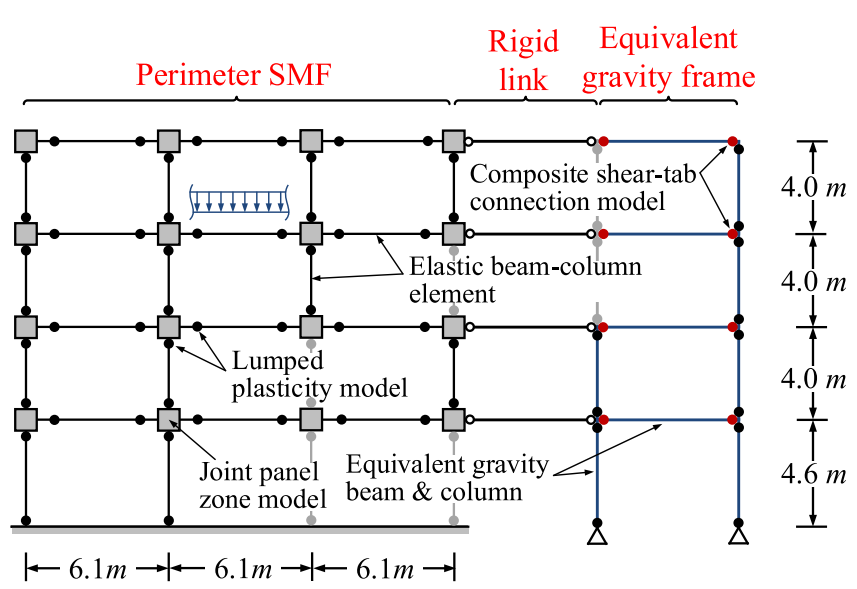

(a)

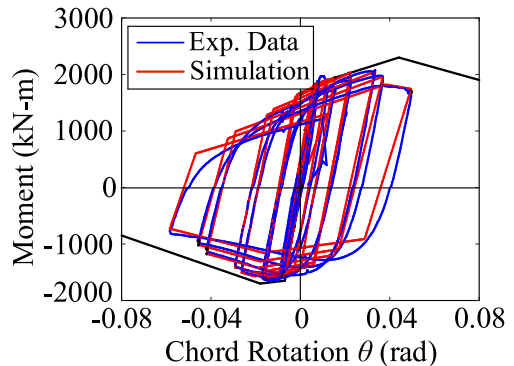

(b)

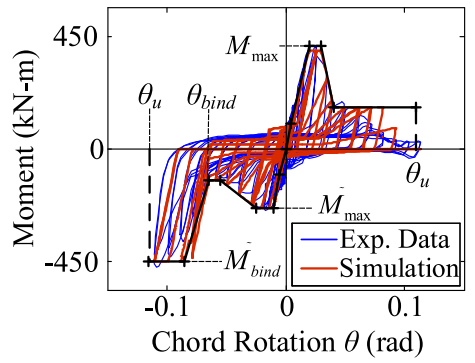

(c)

Figure 3. Example of analytical model representation for steel frame buildings with special moment frames: (a) two-dimensional analytical model for the 4-story steel frame building ( $C G$-model); (b) moment-chord rotation relation for composite beam with reduced beam sections (data from [45]); and (c) moment-chord rotation relation for composite beam as part of a single-plate shear tab connection (data from [46]).

of large scale factors may be observed to trace the collapse resistance of a frame building based on IDA. Luco and Bazzurro [53] concluded that this typically introduces a conservative bias in the predicted demands. For this reason, Haselton et al. [54] provide a factor to correct the median collapse capacity $S_{a}\left(T_{1}, 5 \%\right)$. In order to accommodate the same issue the approach discussed in Haselton et al. [54] was employed.

The EDPs of interest [i.e., peak response quantities for each story such as peak story drift ratios (SDRs) or peak absolute floor acceleration (PFAs), and residual story drift ratios (RSDRs)] are obtained for each ground motion over a wide range of seismic intensities from elastic behavior through the occurrence of structural collapse. Figures 4(a) and (b) depict the peak SDRs and PFAs versus $I M$ as a function of $S_{a}\left(T_{1}, 5 \%\right)$, respectively, for the 4-story steel frame building with perimeter SMFs ( $C G$-model). The additional vertical axis at the right of each figure is provided and the corresponding spectral acceleration is normalized with respect to the 5\% damped design-basis spectral acceleration of the 4-story steel frame building. In the same figures we have superimposed the 16th, 50th, and 84th percentile values based on the set of 44 ground motions discussed earlier. Based on these results, a collapse fragility curve is computed per numerical model representation that describes the probability of structural collapse as a function of $S_{a}\left(T_{1}, 5 \%\right)$. Figures $4(\mathrm{c})$ and (d) illustrate the collapse fragility curves for the five $C G$ - and $B$-models, respectively, of the archetype steel frame buildings considered in this paper. From these figures, $C G$-models tend to have a much larger collapse resistance compared to that obtained from $B$-models. This is due to the fact that the destabilizing effects of the gravity framing system are explicitly captured within a $C G$-model [29].

\section{EXPECTED LOSSES CONDITIONED ON SEISMIC INTENSITY}

Shown in Figure 5 are the total expected losses for the 4- and 12-story archetype buildings with SMFs designed with SCWB $>1.0$ as a function of the seismic intensity, $S_{a}\left(T_{1}, 5 \%\right)$. The total expected losses are normalized with respect to the building total replacement cost (see Table I). The computations in Figure 5 are based on EDPs that are computed from $B$-model representations. 


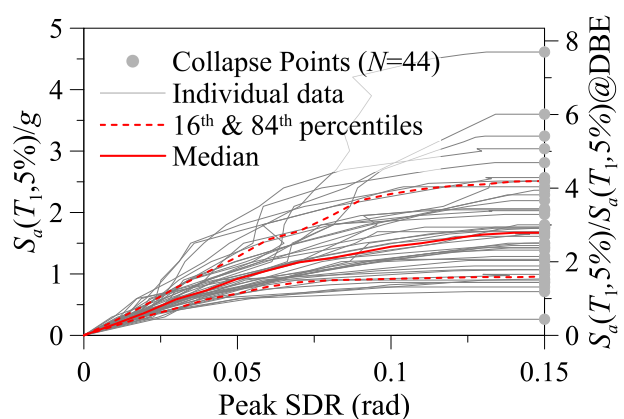

(a)

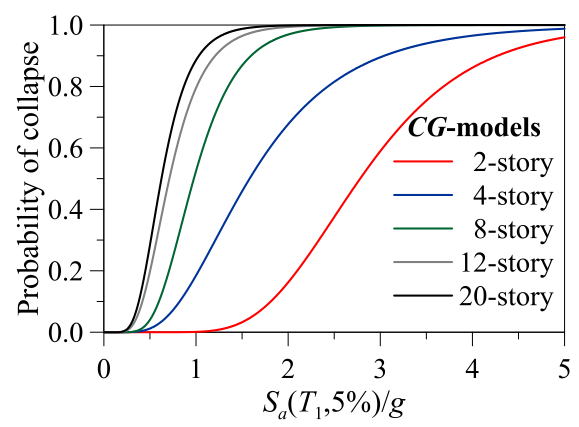

(c)

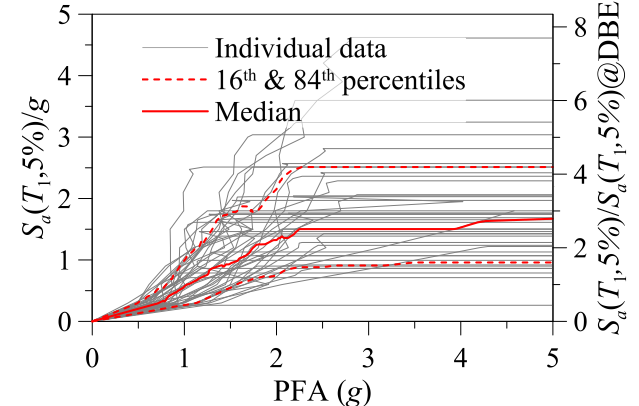

(b)

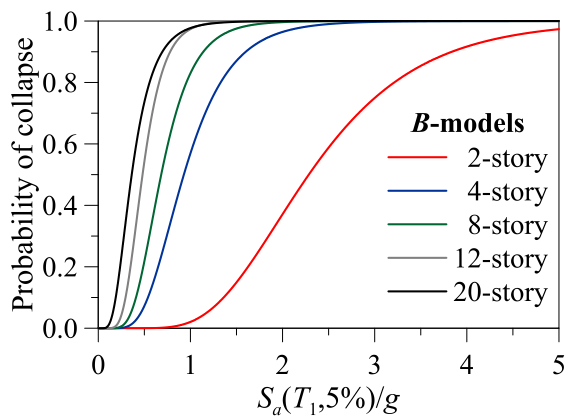

(d)

Figure 4. Critical engineering demand parameters and collapse fragility curves for steel frame buildings with special moment frames. DBE, design-basis earthquake; PFA, peak absolute floor acceleration; SDR, story drift ratio

The additional horizontal axes at the top of each figure illustrate the seismic intensity normalized with respect to the design-basis earthquake (DBE) corresponding to $S_{a}\left(T_{1}, 5 \%\right)$ at DBE hazard level of $0.50 \mathrm{~g}$ and $0.28 \mathrm{~g}$, respectively, for the 4- and 12-story archetype buildings. This is done such that losses can be put into perspective with the DBE. The total-loss curves shown in Figure 5 are also known as loss vulnerability curves $[14,16]$. In the same figure, the total expected losses are further disaggregated into economic losses arising from possible consequences for a building that experienced an earthquake (i.e., structural and non-structural component repairs are necessary, demolition should take place given that building collapse has not occurred and building collapse occurred). Referring to Figure 5, the steel frame building total-loss vulnerability curves reveal that they increase linearly with respect to the seismic intensity up to approximately $50 \%$ of $S_{a}\left(T_{1}, 5 \%\right)$ at the DBE hazard level. From the same figure, the economic losses due to non-structural component repair are the fundamental contributors to the expected total losses until the DBE seismic intensity regardless of the number of stories of a steel frame building with SMFs. This is consistent with prior reconnaissance investigations for steel frame buildings that utilized MRFs [55-57].

From Figure 5, structural repair losses start to become important at seismic intensities equal or larger than the DBE primarily due to steel beam flexural yielding. An important contributor to earthquake-induced losses in steel frame buildings with steel SMFs is the loss associated with building demolition. In particular, at seismic intensities associated with $1.5 \times \mathrm{DBE}$ [i.e., equivalent to a maximum considered earthquake (MCE) in urban California] modern steel frame building economic losses are not necessarily controlled by structural collapse but by excessive RSDRs. Based on a comparison of Figures 5(a) and (b), for mid- and high-rise steel SMFs this may be a big concern due to their sensitivity to P-Delta effects [17,58].

The above observations are further elaborated for selected seismic intensities that represent hazard levels of interest to the engineering profession: namely (a) service-level earthquake (SLE: seismic hazard level of 50\% probability of exceedance in 50 years); (b) DBE; and (c) MCE. The effects of the numerical model representation and design consideration in the basis of SCWB ratios on the 


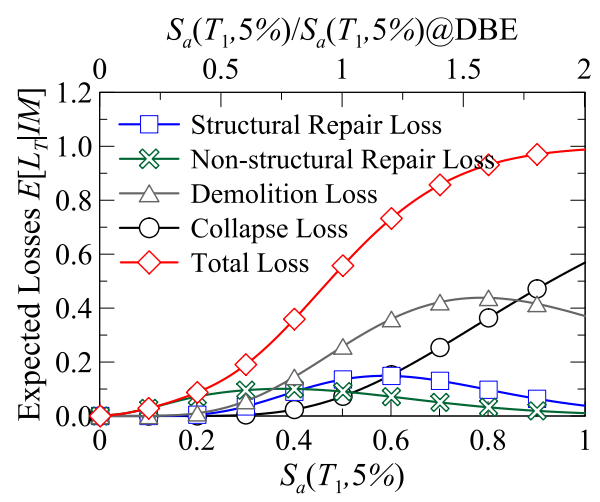

(a) 4-story SMFs with SCWB $>1.0$

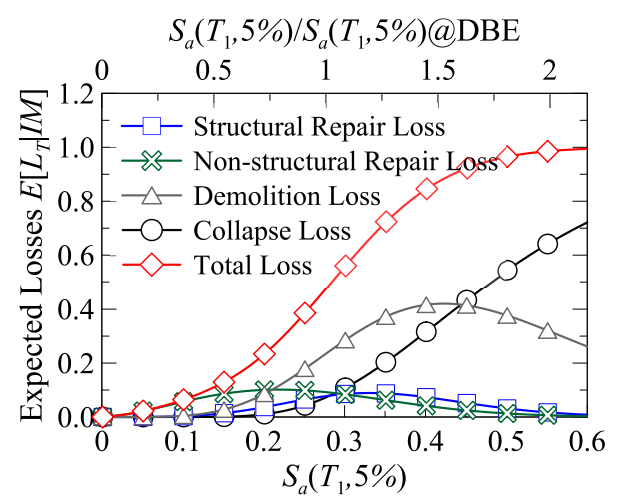

(b) 12-story SMFs with SCWB $>1.0$

Figure 5. Normalized loss vulnerability curves for steel frame buildings with special moment frames conditioned on seismic intensity ( $B$-models). DBE, design-basis earthquake; SCWB, strong-column/weakbeam.

economic losses of steel frame buildings with SMFs conditioned on a seismic intensity are also discussed in detail.

Figures 6 and 7 show the normalized economic losses at the aforementioned three seismic hazard levels based on $B$ - and $C G$-model representations, respectively. In the same figure, the effect of the employed SCWB ratio on the total losses of steel frame buildings with SMFs is illustrated. Similar to Figure 5, economic losses due to non-structural component damage are further disaggregated into drift- and acceleration-sensitive non-structural repairs in order to quantify the primary source of non-structural component repairs. In order to better correlate structural responses with the expected losses at the three considered seismic intensities of interest, Figure 8 illustrates the median peak $E D P$ demands of the 8-story archetype building with steel SMFs designed with SCWB $>1,1.5$ and 2.0 in terms of peak SDRs, PFAs and RSDRs. From Figures 6 and 7, at hazard levels associated with mean annual frequencies $\lambda_{S_{a}}=1.4 \times 10^{-2}$ (i.e., SLE), economic losses in steel frame buildings with SMFs are governed by non-structural component repairs regardless of the steel frame height and the selected numerical model representation of the archetype steel frame building. Referring to Figure 6, losses due to non-structural component repairs are in the range of 5\% of the total replacement cost of the building regardless of its number of stories when $B$-models are employed. Referring to Figure 7, losses due to non-structural damage seem to be closer to $7 \%$ on average, when $C G$-models are employed. This is due to the effect of the composite beam action and gravity framing system on the lateral stiffness of the steel frame buildings. Figure 7 (a) clearly illustrates that repairs due to damage into acceleration-sensitive non-structural components are more extensive than that of drift-sensitive non-structural components. Intuitively, one would expect the opposite due to the inherent flexibility of steel frame buildings with MRFs compared to other commonly used lateral load-resisting systems. However, at very frequent seismic events (i.e., mean annual frequencies in the rate of $\lambda_{S_{a}}=1.4 \times 10^{-2}$ ), code-compliant steel frame buildings with MRFs have more or less a uniform story drift distribution along their height that is less than $0.8 \%$ radians, if the contribution of the gravity framing system is considered. This is shown in Figure 8(a) for the case of the 8-story archetype building. On the other hand, at the same seismic intensities, the median PFAs along the height of a steel frame building with MRFs is on the order of $0.4 g$ [see Figure 8(a)]. Based on these median $E D P$ s, the contribution of losses due to repairs in acceleration-sensitive nonstructural components to the total earthquake-induced losses is larger than that of the drift-sensitive non-structural components for the archetype buildings under consideration. It should be noted that based on Table II, the associated repair cost for acceleration-sensitive non-structural components is much higher than the corresponding one for drift-sensitive components at a given damage state. The same issue is further discussed in Section 6. An interesting point to note is that if losses are evaluated at discrete seismic intensities, only when $C G$-model representations of the archetypes are 

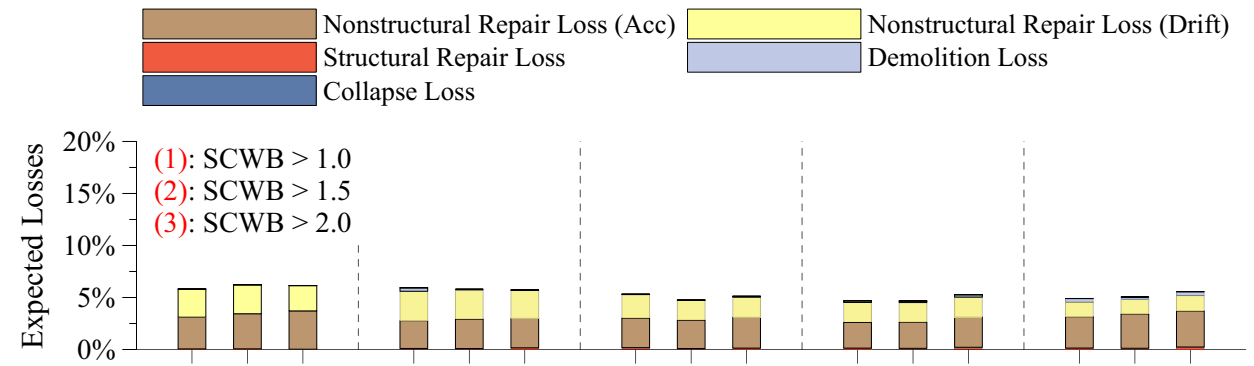

(a) SLE

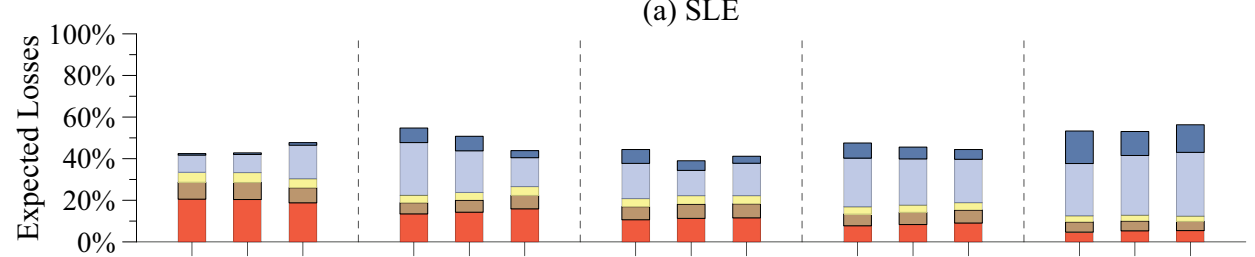

(b) DBE

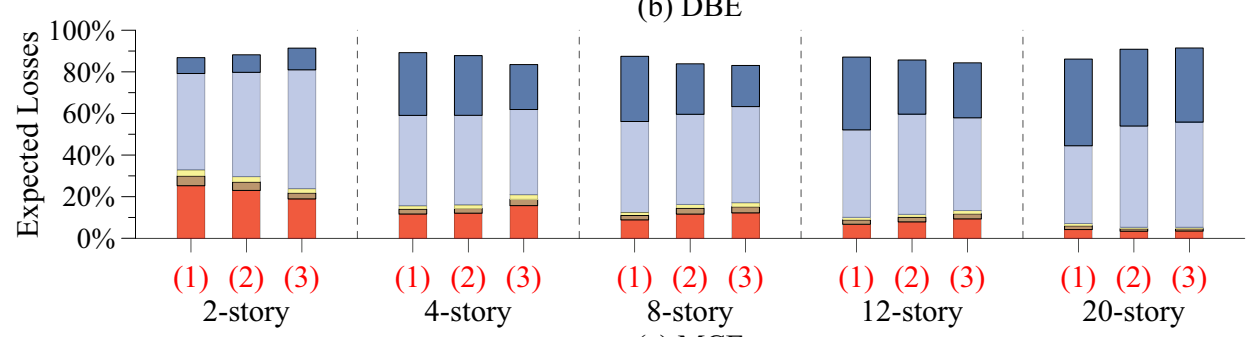

(c) MCE

Figure 6. Normalized expected losses for steel frame buildings with special moment frames at selected seismic intensities ( $B$-models). DBE, design-basis earthquake; MCE, maximum considered earthquake; SCWB, strong-column/weak-beam; SLE, service-level earthquake.

employed it is depicted that repairs due to acceleration-sensitive non-structural components become more controlling than those in drift-sensitive components at SLE seismic intensities.

At hazard levels associated with DBE (i.e., $\lambda_{S_{a}}=2.1 \times 10^{-3}$ ), the contribution of losses due to structural component repairs dominates the normalized expected losses for low-rise steel archetype buildings with SMFs [see Figures 6(b) and 7(b)]. In particular, structural component losses for lowrise steel frame buildings are in the range of $20 \%$ of their total replacement cost regardless of the employed analytical model. For mid- and high-rise steel frame buildings losses due to structural and non-structural repairs are comparable regardless of the selected numerical model representation of the archetype steel frame building (i.e., $B$ - or $C G$-model). From a careful examination of the collapse mechanisms of the steel frame buildings examined in this paper, losses due to structural component repairs in low-rise steel SMFs are more evenly spread along their height (i.e., formation of beam mechanism) compared to mid- and high-rise steel SMFs. This is due to the fact that at seismic intensities associated with extreme earthquakes, mid- and high-rise steel SMFs tend to form collapse mechanisms that involve bottom stories only due to drift migration because of P-Delta effects [17-19]. In this case, if a SCWB $>1.5$ or 2.0 is employed in the seismic design process, such mechanisms can be avoided as shown in Figures 8(b) and (c) based on the median peak SDRs along the height of the 8-story archetype.

From Figures 6(b) and (c), based on EDPs computed from $B$-models (i.e., bare frame only) losses due to demolition followed by those associated with structural collapse become fairly important at DBE hazard levels and dominate the total expected losses at hazard levels associated with MCE (i.e., $\lambda_{S_{a}}=4.0 \times 10^{-4}$ ) for mid- and high-rise steel frame buildings with SMFs. This is attributed to their flexibility; therefore P-Delta effects have a profound influence on the steel buildings' response to an earthquake such as permanent deformation and structural collapse. However, the above 

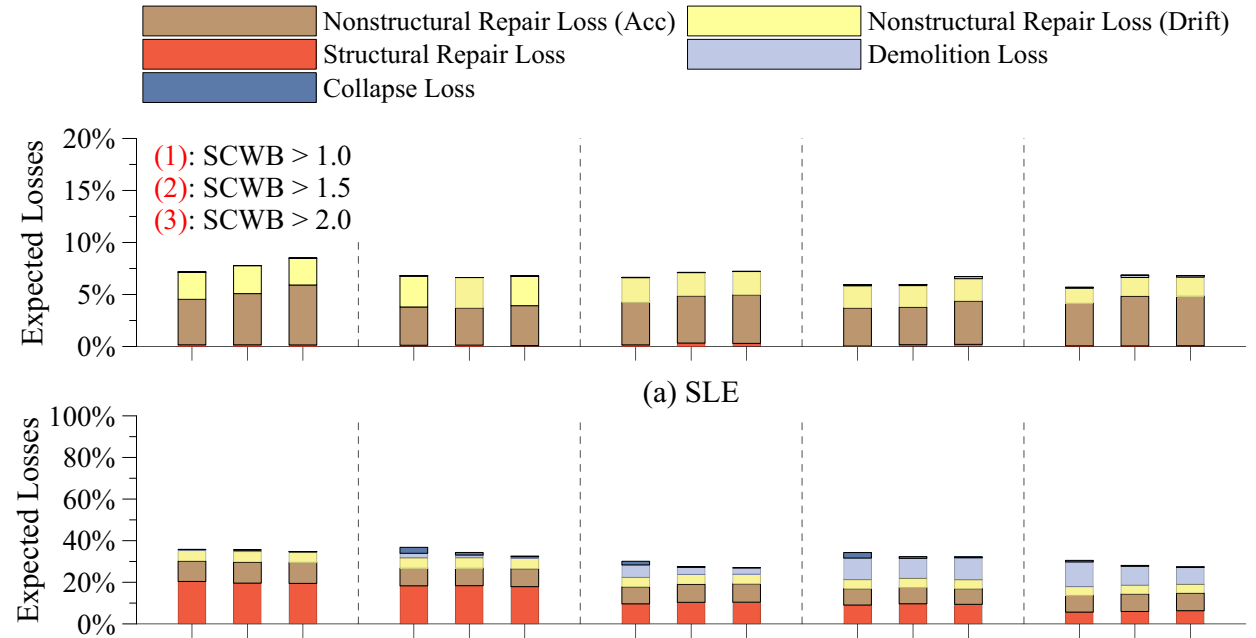

(b) DBE

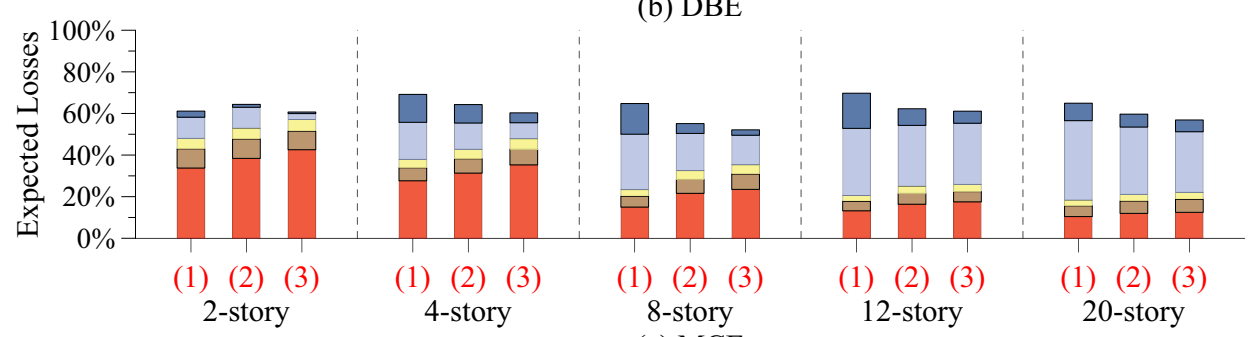

(c) MCE

Figure 7. Normalized expected losses for steel frame buildings with special moment frames at selected seismic intensities ( $C G$-models). DBE, design-basis earthquake; MCE, maximum considered earthquake; SCWB, strong-column/weak-beam; SLE, service-level earthquake.

observation does not hold true when EDPs are based on $C G$-models. This is primarily attributed to the destabilization of P-Delta effects that is explicitly captured because of the consideration of the gravity framing system within the analytical model representation of an archetype building. For the same reason, losses due to structural component damage are overestimated by at least $50 \%$ in steel frame buildings subjected to seismic events with low probabilities of occurrence (i.e., MCE) when $B$-model representations are employed [see Figures 6(c) and 7(c)]. The above mentioned observations indicate the importance of modeling the effect of gravity framing on the overall seismic performance of steel frame buildings with SMFs.

At hazard levels associated with a MCE (i.e., $\lambda_{S_{a}}=4.0 \times 10^{-4}$ ) losses due to demolition given that building collapse has not occurred followed by structural repair losses tend to dominate the total expected earthquake-induced losses in the steel frame buildings with SMFs regardless of their height. Losses due to dynamic collapse also become an important contributor to the total expected losses. This agrees with earlier findings on code-compliant RC frame buildings [16]. From a comparison of Figures 6(c) and 7(c), it should be emphasized that the above-mentioned economic loss contributors may be significantly overestimated in mid- and high-rise steel frame buildings with SMFs if the composite gravity framing system is not considered in the analytical model representation of the archetype building. For instance, losses due to demolition and collapse for the 12-story steel frame building designed with a SCWB $>1.0$ under a MCE hazard level decrease by $23 \%$ and $52 \%$, respectively, relative to those computed based on a $B$-model representation of the same building [see Figures 6(c) and 7(c)]. Note that if the strong axis of the gravity columns would be oriented in parallel with the E-W loading direction of the archetypes, then the additional contribution to the system overstrength and stiffness relative to that of the $B$-model would be $30 \%$ and $20 \%$, respectively, as discussed in Flores et al. [28]. Therefore, in this case, losses due to 
demolition as well as collapse would be expected to be even less than those computed herein. On the other hand, losses due to acceleration-sensitive non-structural component damage in frequently occurring seismic intensities (i.e., SLE) would be expected to be slightly higher than those reported herein. This issue deserves more attention and should be examined in future studies.

In this paragraph, the effect of the employed SCWB ratio on the earthquake-induced losses of steel frame buildings with SMFs is quantified. The discussion is facilitated based on results from Figures 7 and 8(c) (i.e., use of $C G$-models). From these figures, the use of SCWB $>2.0$ generally decreases losses due to consequences of demolition and collapse, while the contribution of losses due to structural component repairs to total economic losses increases. These benefits are more pronounced for mid-rise steel frame buildings with SMFs (i.e., 8- to 12-stories). For instance, the demolition and collapse losses in the 8-story steel building designed with SCWB $>2.0$ decrease by $47 \%$ and $68 \%$, respectively, relative to those of the building with SCWB $>1.0$. From Figure 8(c), at the MCE seismic intensity, the median residual story drift ratio from all stories in the 8story archetype is reduced by a factor of 1.4. Furthermore, the 8-story archetype building collapses in 4 out of 44 ground motions scaled at the MCE seismic intensity, when a SCWB $>1.0$ is employed. On the other hand, when a higher SCWB ratio is employed, the 8-story archetype does not collapse in any of the ground motions at MCE. Based on Figure 7, the effectiveness of the increased SCWB in reducing the losses due to collapse and demolition in high-rise steel frame buildings (i.e., larger than 12-stories) with SMFs is not large. This is attributed to P-Delta effects. These observations are consistent with prior analytical studies related to the collapse assessment of steel SMFs under earthquakes [20]. An increase of the employed SCWB ratio generally prevents or at least delays bottom story collapse mechanisms in steel SMFs under extreme earthquakes and assists in distributing evenly the lateral deformation demands in more stories along the height of a steel frame building with SMFs as shown in Figure 8(c).

\section{EXPECTED ANNUAL LOSSES}

In this section, earthquake-induced losses in the archetype buildings are evaluated through the expected annual losses (EALs). This quantity is computed by integrating the vulnerability curve of a frame building (see Figure 5) given a seismic intensity over all possible values of the ground motion intensity, that is, the seismic hazard curve (see Figure 2). The $E A L$ indicates an average yearly amount that may be spent to earthquake damage repairs. It is interesting to note that $E A L$ results weight all possible levels of seismic hazard by taking into account their probability of occurrence. This indicates that more frequent seismic events rather than those with low probabilities of occurrence may strongly influence this loss-metric. The EAL is computed as follows,

$$
E A L=E\left[L_{T}\right]=\int_{0}^{\infty} E\left[L_{T} \mid I M\right] \mathrm{d} \lambda_{S_{a}}(I M)=\int_{0}^{\infty} E\left[L_{T} \mid I M\right]\left|\frac{\mathrm{d} \lambda_{S_{a}}(I M)}{\mathrm{d} I M}\right| \mathrm{d} I M
$$

in which $\lambda_{S_{a}}(I M)$ is the mean annual frequency of the ground motion intensity; and $\left|\mathrm{d} \lambda_{S_{a}}(I M) / \mathrm{d} I M\right|$ is the derivative of the seismic hazard curve (see Figure 2). For the subsequent discussion, $E A L$ values for all the archetype steel frame buildings discussed in Section 3 are normalized with respect to their total replacement cost as summarized in Table I.

Figure 9 illustrates graphically the normalized $E A L$ results for the 4- and 12-story steel frame buildings with SMFs. For comparison purposes $E A L$ results are computed based on both the $B$-and $C G$-model representations of the archetype buildings discussed in this paper. In addition, Figure 9 illustrates the sensitivity of EALs with respect to the employed SCWB ratio that is used in the seismic design of steel SMFs. From Figure 9, the EALs range from $0.38 \%$ to $0.53 \%$ of the replacement cost of the respective building of interest. In order to "digest" these values, the $E A L$ results are further disaggregated into losses due to acceleration- and drift-sensitive non-structural components, structural repair, and demolition as well as losses due to structural collapse. Figure 9 illustrates that the EALs in steel frame buildings with SMFs are dominated by non-structural repair costs regardless of the employed analytical model representation (i.e., $B$-versus $C G$-models). 

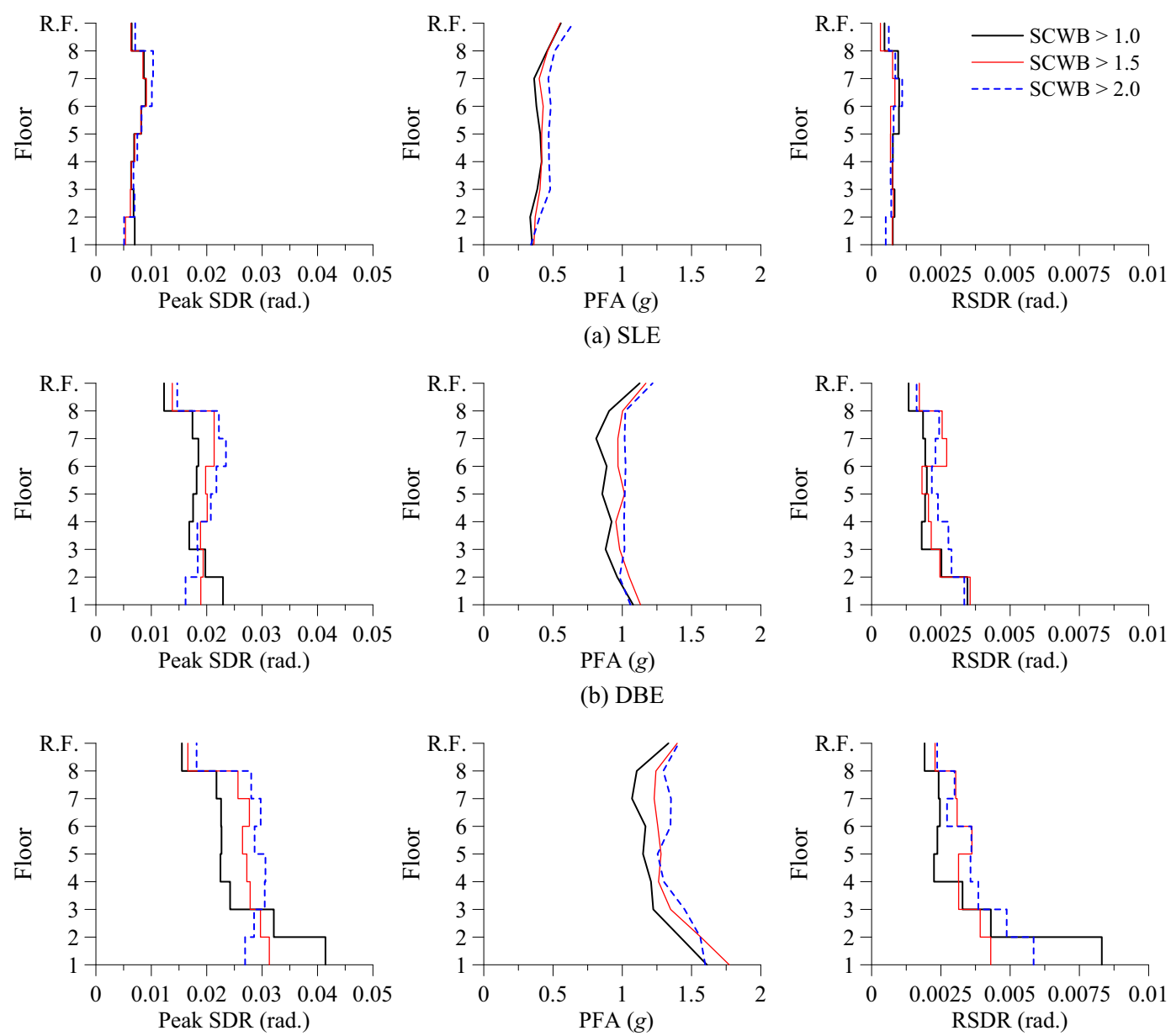

(c) $\mathrm{MCE}$

Figure 8. Median values of engineering demand parameters of interest along the building height for $C G$ models of the 8-story steel frame buildings with special moment frames at selected seismic intensities. DBE, design-basis earthquake; MCE, maximum considered earthquake; PFA, peak absolute floor acceleration; RSDR, residual story drift ratio; SCWB, strong-column/weak-beam; SDR, story drift ratio; SLE, servicelevel earthquake.

This is attributed to the fact that the economic losses for the archetypes are governed by nonstructural component repairs due to more frequently occurring earthquakes (i.e., range of SLE seismic intensities). Therefore, such earthquakes significantly affect EALs over the life expectancy of a building.

From Figure 9, repair losses in acceleration-sensitive non-structural components primarily dominate the EALs, followed by losses due to repair of drift-sensitive non-structural components. Note that the contribution of acceleration-sensitive non-structural components to the $E A L$ increased appreciably when incorporating the composite gravity framing system into the analytical model representation of a steel frame building regardless of its number of stories (see Table IV). This is due to the effects of the composite gravity framing system on the lateral stiffness of a steel frame building [20,29]. Naturally, an analytical model that incorporates the composite gravity framing system in addition to the primary lateral load-resisting system would be stiffer than a bare frame model. This can be seen from Table IV that summarizes the first mode periods of all the archetype buildings considered in this paper. In order to further explain this observation, Figures 10(a) and (b) illustrate the counted median, $16^{\text {th }}$ and $84^{\text {th }}$ percentiles of the peak SDRs and PFAs along the height of the 12-story steel frame building based on its $B$ - and $C G$-models, respectively, for the set of 44 
records scaled to represent the SLE seismic intensity (i.e, 50\% probability of occurrence over 50 years of building life expectancy). From this figure, once the composite gravity framing system is considered in the analytical model representation of the 12-story building the predicted peak SDRs along the height of the building become $12 \%$ larger than those predicted from the respective $B$ model. On the other hand, the predicted PFAs along the height of the same building based on its $C G$ model become considerably larger than the predicted ones based on the $B$-model (i.e., $0.4 g$ versus $0.3 g$, respectively). Due to this increase, the likelihood of damage to acoustic ceiling, sprinklers as well as elevators becomes much higher based on the fragility curves of the aforementioned components as shown in Table II. Same observations hold true for all the examined designs. This can be seen from Table IV that summarizes the EAL values for all the considered cases. These simple comparisons indicate that when the $E A L$ is employed as a loss-metric, earthquake-induced economic losses in steel frame buildings due to non-structural component repairs may be underestimated if the composite gravity framing system is neglected from the analytical model representation of the steel frame building under consideration.

From Figure 9, when earthquake-induced losses are seen through the EALs, the effect of the employed SCWB ratio on the EAL becomes negligible. This is due to the fact that this design criterion would mostly affect the formation of collapse mechanisms involving steel columns at seismic intensities associated with low-probability of occurrence earthquake events over a 50-year building life expectancy (e.g., MCE). On the other hand, $E A L$ is strongly affected by more frequently occurring earthquakes and emphasizes on the importance of considering non-structural repair losses given no collapse. In that sense, losses conditioned at a given seismic intensity may be a better metric than EAL to evaluate the efficiency of the employed SCWB ratio in terms of reducing losses due building demolition and structural collapse.

\section{PRESENT VALUE OF LIFE-CYCLE COSTS}

In addition to a building's $E A L$ it is often desirable to evaluate the present value of life-cycle costs associated with earthquake-induced losses. This can be done through the present value, P.V., of lifecycle costs that is simply computed by multiplying a buildings $E A L$ times its expected lifespan, $T$. This value is then discounted by assuming a discount rate, $r$, such that the equivalent present value

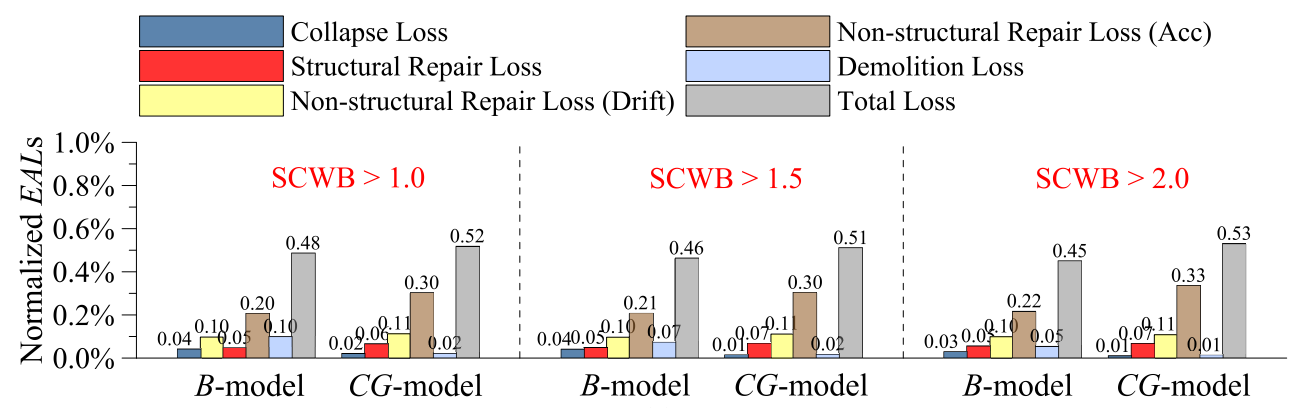

(a) 4-story

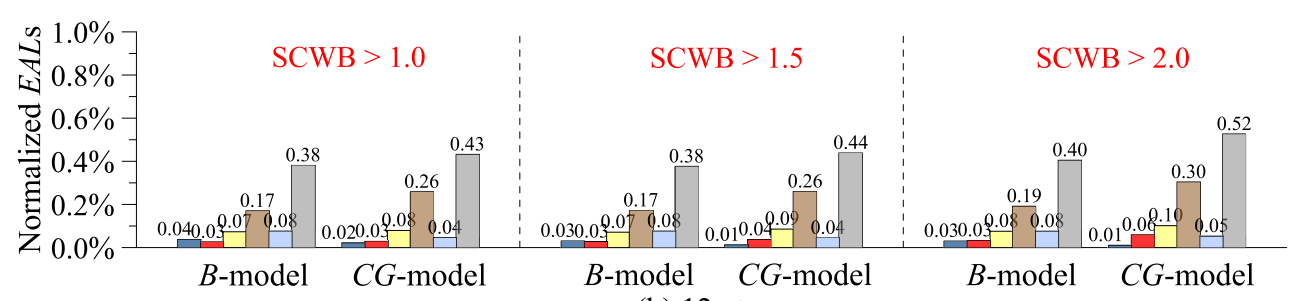

(b) 12-story

Figure 9. Illustration of normalized expected annual losses for steel frame buildings with special moment frames. SCWB, strong-column/weak-beam. 
Table IV. Dynamic characteristics and constituents of expected annual losses for archetype buildings.

\begin{tabular}{|c|c|c|c|c|c|c|c|c|c|}
\hline \multirow{3}{*}{$\begin{array}{l}\text { No. of } \\
\text { stories }\end{array}$} & \multirow{3}{*}{$\begin{array}{l}\text { SCWB } \\
\text { ratio }\end{array}$} & \multirow{3}{*}{ Model } & \multirow{3}{*}{$T_{1}$} & \multicolumn{6}{|c|}{ Constituents of expected annual losses (\%) } \\
\hline & & & & Non- & ural Repair & Structural & Demolition & Collapse & Total \\
\hline & & & & Acc & Drift & Repair & losses & losses & losses \\
\hline \multirow{6}{*}{2} & \multirow{2}{*}{$>1.0$} & $B$ & 0.88 & 0.29 & 0.10 & 0.06 & 0.04 & 0.01 & 0.50 \\
\hline & & $C G$ & 0.76 & 0.41 & 0.11 & 0.07 & 0.01 & 0.01 & 0.59 \\
\hline & \multirow{2}{*}{$>1.5$} & $B$ & 0.83 & 0.33 & 0.11 & 0.05 & 0.04 & 0.01 & 0.54 \\
\hline & & $C G$ & 0.72 & 0.46 & 0.12 & 0.06 & 0.01 & 0.00 & 0.66 \\
\hline & \multirow{2}{*}{$>2.0$} & $B$ & 0.79 & 0.35 & 0.10 & 0.05 & 0.05 & 0.01 & 0.55 \\
\hline & & $C G$ & 0.68 & 0.56 & 0.12 & 0.06 & 0.00 & 0.00 & 0.74 \\
\hline \multirow{6}{*}{4} & \multirow{2}{*}{$>1.0$} & $B$ & 1.51 & 0.20 & 0.10 & 0.05 & 0.10 & 0.04 & 0.48 \\
\hline & & $C G$ & 1.25 & 0.30 & 0.11 & 0.06 & 0.02 & 0.02 & 0.52 \\
\hline & \multirow{2}{*}{$>1.5$} & $B$ & 1.48 & 0.21 & 0.10 & 0.05 & 0.07 & 0.04 & 0.46 \\
\hline & & $C G$ & 1.22 & 0.30 & 0.11 & 0.07 & 0.02 & 0.01 & 0.51 \\
\hline & \multirow{2}{*}{$>2.0$} & $B$ & 1.44 & 0.22 & 0.10 & 0.05 & 0.05 & 0.03 & 0.45 \\
\hline & & $C G$ & 1.19 & 0.33 & 0.11 & 0.07 & 0.01 & 0.01 & 0.53 \\
\hline \multirow{6}{*}{8} & \multirow{2}{*}{$>1.0$} & $B$ & 2.00 & 0.20 & 0.09 & 0.04 & 0.06 & 0.04 & 0.43 \\
\hline & & $C G$ & 1.72 & 0.32 & 0.10 & 0.04 & 0.03 & 0.02 & 0.51 \\
\hline & \multirow{2}{*}{$>1.5$} & $B$ & 1.93 & 0.19 & 0.07 & 0.04 & 0.05 & 0.03 & 0.39 \\
\hline & & $C G$ & 1.66 & 0.35 & 0.11 & 0.05 & 0.02 & 0.01 & 0.54 \\
\hline & \multirow{2}{*}{$>2.0$} & $B$ & 1.87 & 0.21 & 0.07 & 0.04 & 0.07 & 0.03 & 0.42 \\
\hline & & $C G$ & 1.61 & 0.39 & 0.10 & 0.05 & 0.02 & 0.01 & 0.56 \\
\hline \multirow{6}{*}{12} & \multirow{2}{*}{$>1.0$} & $B$ & 2.70 & 0.17 & 0.07 & 0.03 & 0.08 & 0.04 & 0.38 \\
\hline & & $C G$ & 2.35 & 0.26 & 0.08 & 0.03 & 0.04 & 0.02 & 0.43 \\
\hline & \multirow{2}{*}{$>1.5$} & $B$ & 2.62 & 0.17 & 0.07 & 0.03 & 0.08 & 0.03 & 0.38 \\
\hline & & $C G$ & 2.28 & 0.26 & 0.09 & 0.04 & 0.04 & 0.01 & 0.44 \\
\hline & \multirow{2}{*}{$>2.0$} & $B$ & 2.50 & 0.19 & 0.08 & 0.03 & 0.08 & 0.03 & 0.40 \\
\hline & & $C G$ & 2.16 & 0.30 & 0.10 & 0.06 & 0.05 & 0.01 & 0.52 \\
\hline \multirow{6}{*}{20} & \multirow{2}{*}{$>1.0$} & $B$ & 3.44 & 0.21 & 0.06 & 0.02 & 0.09 & 0.06 & 0.43 \\
\hline & & $C G$ & 3.08 & 0.29 & 0.07 & 0.03 & 0.05 & 0.01 & 0.44 \\
\hline & \multirow{2}{*}{$>1.5$} & $B$ & 3.32 & 0.24 & 0.06 & 0.02 & 0.09 & 0.04 & 0.45 \\
\hline & & $C G$ & 2.97 & 0.40 & 0.08 & 0.02 & 0.05 & 0.01 & 0.55 \\
\hline & \multirow{2}{*}{$>2.0$} & $B$ & 3.22 & 0.26 & 0.06 & 0.02 & 0.10 & 0.05 & 0.50 \\
\hline & & $C G$ & 2.87 & 0.38 & 0.08 & 0.02 & 0.04 & 0.01 & 0.53 \\
\hline
\end{tabular}

SCWB, strong-column/weak-beam

of $T$-years of earthquake-induced losses may be computed. Equation (6) below computes $P$. V., for a building as follows,

$$
P . V .=E A L \cdot \sum_{i=1}^{T}(1+r)^{-i}
$$

Figure 11 illustrates the present value of losses for $C G$-models of steel frame buildings at a discounted rate $r=3 \%$. For the sake of computations, a 50-year building lifespan was considered because the archetypes discussed in this paper represent office buildings (see Section 3). The $C G$ model representations of the archetype steel frame buildings are employed for the computations of the present value of life-cycle costs. From Figure 11, the present values vary from about $10 \%$ to $20 \%$ of the total replacement cost of a building. Typically, the present value of life-cycle costs for low-rise steel frame buildings are larger than those for mid- and high-rise steel frame buildings. This is due to the severity of the respective hazard curves at lower periods of vibration as shown in Figure 2.

From Figure 11, the effects of the employed SCWB ratio on the present value of life-cycle costs seem to be appreciable for low-rise steel frame buildings with SMFs. This arises from the fact that a higher SCWB ratio would typically result into a stiffer SMF design. Therefore, the contribution of acceleration-sensitive non-structural losses to the present value would then increase as discussed in Section 6 for EALs. However, the stiffening effect is less pronounced in mid- and high-rise steel frame buildings compared to low-rise buildings because of the use of deeper steel beams [59]. 


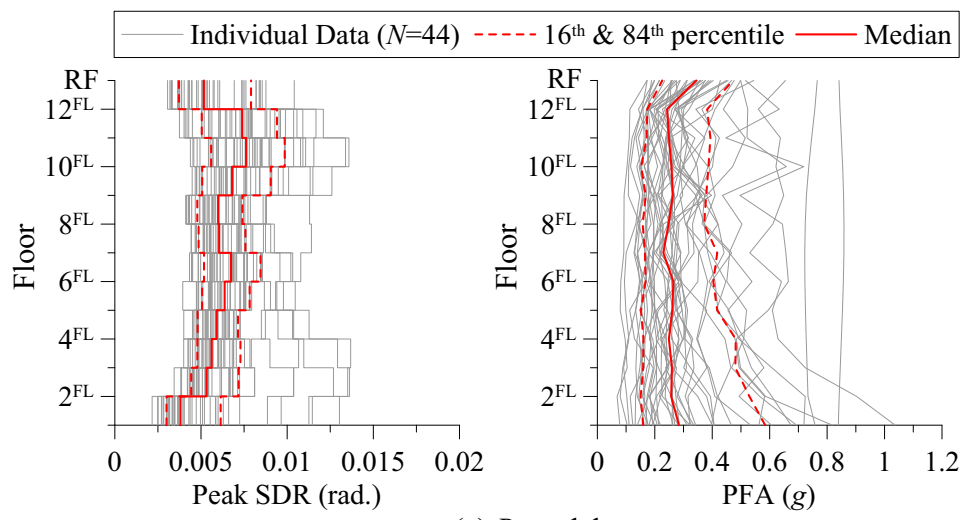

(a) B-model
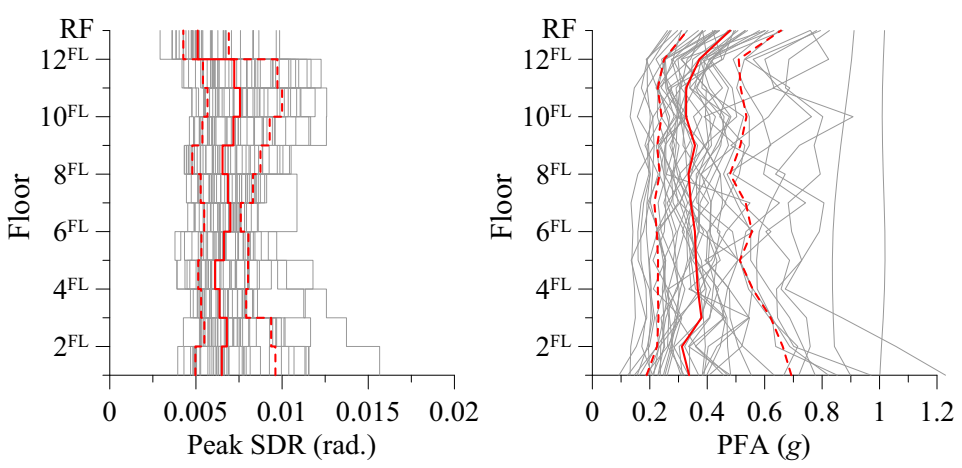

(b) $C G$-model

Figure 10. Engineering demand parameters from the 12-story buildings with/without the gravity framing $(B$ and $C G$-models). PFA, peak absolute floor acceleration; SDR, story drift ratio.

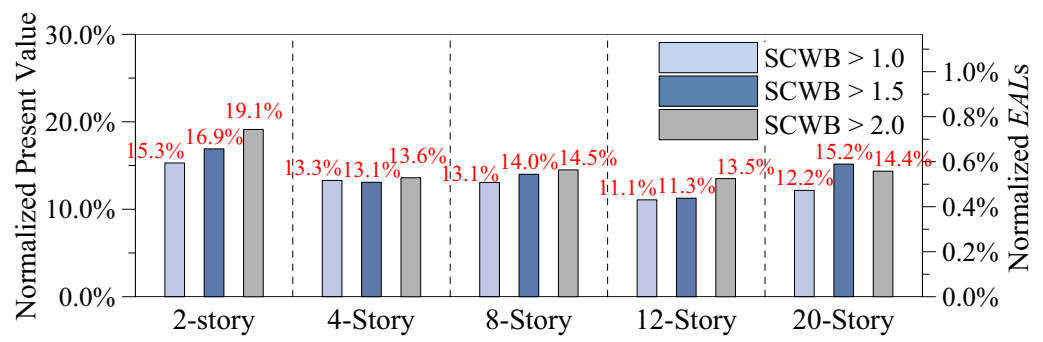

Figure 11. Normalized present value for $C G$-models of steel buildings with special moment frames. EALs, expected annual losses; SCWB, strong-column/weak-beam.

\section{CONCLUSIONS}

This paper evaluated the earthquake-induced losses in modern steel frame buildings that utilize special moment frames (SMFs) as their primary lateral load-resisting system. The steel frame buildings were assumed to be located in a highly seismic region in urban California. For this purpose, results from collapse analyses of archetype steel frame buildings with SMFs ranging from 2- to 20-stories were utilized. The loss-assessment methodology that was employed explicitly considered the residual deformations along the height of a building that did not collapse in the aftermath of an earthquake, in addition to peak story drift ratios (SDRs) and peak absolute floor accelerations (PFAs) for a wide range of seismic intensities including frequent seismic events as well as design and maximum considered events. Economic losses were evaluated based on 
three different loss-metrics, namely: (i) expected losses conditioned on the seismic intensity; (ii) expected annual losses (EALs); and (iii) present value of life-cycle costs. The effect of the analytical model representation of the archetype steel frame building on the earthquake-induced losses was investigated. In particular, two options were considered. The first one involved an analytical model that represented the bare structural components of the steel SMF (noted as $B$-model); the second one explicitly considered the composite beam effects and the interior gravity framing system of the archetype steel frame buildings (noted as $C G$-model). The influence of the employed strongcolumn/weak-beam (SCWB) ratio on the earthquake-induced losses in the archetype buildings was also examined. The main findings of the comprehensive work summarized in this paper are as follows:

(1) At seismic intensities associated with service and/or design-basis earthquakes damage to nonstructural content dominates steel frame building earthquake losses regardless of the number of stories, the employed loss-metric and the analytical model representation of the steel frame building.

(2) When the composite beam effects and the interior gravity framing are neglected from the analytical model representation of a steel frame building with SMFs the contributions of the non-structural component repairs to total expected losses are underestimated when the $E A L$ is employed as a loss-metric. This is due to the fact that acceleration-sensitive non-structural content repairs are underestimated.

(3) At seismic intensities associated with maximum considered earthquakes, losses due to building demolition and collapse may be overestimated by $50 \%$ or more when the employed building analytical model considers the bare SMF only. On the other hand, losses due to structural damage repairs may be underestimated by $50 \%$. The reason is that the gravity force supported by the interior gravity framing system that contributes to the destabilizing P-Delta effects is not considered in $B$-models. Therefore, the computed residual story drift ratios along the height of a steel frame building are larger than what they would be in reality.

(4) Losses due to demolition and collapse in low- to mid-rise steel frame buildings with SMFs designed with a SCWB $>2.0$ are reduced by a factor of two compared to those in the same SMFs designed with a SCWB $>1.0$ (i.e., current seismic code provisions). However, when earthquake-induced losses are seen through the EALs the effect of the employed SCWB ratio on the EAL seems negligible. The reason is that the employed SCWB ratio mostly affects the formation of collapse mechanisms involving steel columns in steel SMFs under extreme seismic events (i.e., small probability of occurrence over the building lifespan). These events do not have a strong influence on $E A L s$ compared to frequently occurring earthquakes.

(5) The present value of life-cycle costs for steel frame buildings with SMFs varies from about 10 to $20 \%$ of their total replacement cost. Low-rise steel frame buildings seem to have larger present value of life-cycle costs than mid- and high-rise ones. This is due to the severity of the hazard curves at lower predominant periods or vibration.

The earthquake-induced losses for the archetype buildings presented in this paper are dependent on the employed component fragility curves summarized in Table II. Based on new experimental data that will eventually become available, refined component fragilities should be employed in future studies associated with building-specific loss estimation studies. According to the authors' opinion, the composite gravity framing system should always be considered as part of the analytical model representation of a steel frame building with SMFs for more realistic earthquake-induced loss computations. Finally, a combination of loss-metrics should be employed for the computation of earthquake-induced losses depending on the seismic performance level of interest.

\section{ACKNOWLEDGEMENTS}

This study is based on work supported by the Fonds de recherché du Québec - Nature et technologies, Projet de Recherché en Equipe, Award No. FQRNT 2013-PR-167747 as well as École Polytechnique Fédérale de Lausanne (EPFL). The financial support is gratefully acknowledged. The authors also thank Dr. Ahmed Elkady for sharing his collapse analysis results for steel frame buildings with special moment frames. Any 
opinions, findings, and conclusions or recommendations expressed in this paper are those of the authors and do not necessarily reflect the views of the sponsors.

\section{REFERENCES}

1. AIJ. Structural steelwork specification for building construction. JASS 6. Architecture Institute of Japan: Tokyo, Japan, 2007.

2. CSA. Design of steel structures. CAN/CSA S16-09. Canadian Standards Association: Mississauga, ON, Canada, 2009.

3. AISC. Seismic provisions for structural steel buildings. ANSI/AISC 341-10. American Institute of Steel Construction: Chicago, IL, 2010.

4. Westenenk B, de la Llera JC, Besa JJ, Jünemann R, Moehle J, Lüders C, Inaudi JA, Elwood KJ, Hwang SJ. Response of reinforced concrete buildings in Concepción during the Maule earthquake. Earthquake Spectra 2012; 28(S1):S257-S280, DOI:10.1193/1.4000037.

5. Okazaki T, Lignos DG, Midorikawa M, Ricles JM, Love J. Damage to steel buildings observed after the 2011 Tohoku-Oki earthquake. Earthquake Spectra 2013; 29(S1):S219-S243, DOI:10.1193/1.4000124.

6. Cornell CA, Krawinkler H. Progress and challenges in seismic performance assessment. PEER Center News 2000; 3(2):1-4. URL http://peer. berkeley. edu/news/2000spring/performance.html, [October 2015].

7. FEMA. Seismic performance assessment of buildings, volume 1-methodology. Report No. FEMA P-58-1, prepared by the Applied Technology Council for the Federal Emergency Management Agency, Washington, DC 2012.

8. FEMA. Seismic performance assessment of buildings, volume 2-implementation guide. Report No. FEMA P-58-2, prepared by the Applied Technology Council for the Federal Emergency Management Agency, Washington, DC 2012.

9. Krawinkler H, Miranda E. Performance-based earthquake engineering, chapter 9. Earthquake engineering: from engineering seismology to performance-based engineering, Bozorgnia Y, Bertero VV (eds.). CRC press: Boca Raton, FL, 2004; 9-1 to 9-59.

10. Gunturi SKV. Building-specific earthquake damage estimation. PhD Thesis, Department of Civil and Environmental Engineering, Stanford University, Stanford, CA 1993.

11. Porter KA, Kiremidjian AS, LeGrue JS. Assembly-based vulnerability of buildings and its use in performance evaluation. Earthquake Spectra 2001; 17(2):291-312, DOI:10.1193/1.1586176.

12. Singhal A, Kiremidjian AS. A method for earthquake motion-damage relationships with application to reinforced concrete frames. Blume Center Technical Report No. 119, The John A. Blume Earthquake Engineering Center, Stanford University, Stanford, CA. 1996.

13. Pei S, van de Lindt JW. Methodology for earthquake-induced loss estimation: An application to woodframe buildings. Structural Safety 2009; 31(1):31-42.

14. Ramirez CM, Liel AB, Mitrani-Reiser J, Haselton CB, Spear AD, Steiner J, Deierlein GG, Miranda E. Expected earthquake damage and repair costs in reinforced concrete frame buildings. Earthquake Engineering \& Structural Dynamics 2012; 41(11):1455-1475, DOI:10.1002/eqe.2216.

15. Terzic V, Merrifield S, Mahin SA. Lifecycle cost comparisons for different structural systems designed for the same location. Proceedings of the 15th World Conference on Earthquake Engineering (15WCEE), Lisbon, Portugal, September 24-28, 2012.

16. Ramirez CM, Miranda E. Significance of residual drifts in building earthquake loss estimation. Earthquake Engineering \& Structural Dynamics 2012; 41(11):1477-1493, DOI:10.1002/eqe.2217.

17. Gupta A, Krawinkler H. Seismic demands for the performance evaluation of steel moment resisting frame structures. Blume Center Technical Report No. 132, The John A. Blume Earthquake Engineering Center, Stanford University, Stanford, CA. 1999.

18. NIST. Applicability of nonlinear Multiple-Degree-of-Freedom modeling for design. Report No. NIST GCR 10917-9, prepared by the NEHRP Consultants Joint Venture for the National Institute of Standards and Technology, Gaithersburg, MD 2010.

19. Lignos DG, Zareian F, Krawinkler H. A steel component database for deterioration modeling of steel beams with RBS under cyclic loading. Proceedings of ASCE Structures Congress 2010, Orlando, FL, May 12-15, 2010; $1241-$ 1252, DOI: $10.1061 / 41130(369) 113$

20. Elkady A, Lignos DG. Modeling of the composite action in fully restrained beam-to-column connections: implications in the seismic design and collapse capacity of steel special moment frames. Earthquake Engineering \& Structural Dynamics 2014; 43(13):1935-1954, DOI:10.1002/eqe.2430.

21. NIST. Tentative framework for development of advanced seismic design criteria for new buildings. Report No. GCR 12-917-20, prepared by the NEHRP Consultants Joint Venture for the National Institute of Standards and Technology, Gaithersburg, MD 2012.

22. Tesfamariam S, Goda K. Loss estimation for non-ductile reinforced concrete building in Victoria, British Columbia, Canada: effects of mega-thrust $M_{w} 9$-class subduction earthquakes and aftershocks. Earthquake Engineering \& Structural Dynamics 2015; 44(13):2303-2320, DOI:10.1002/eqe.2585.

23. Hwang SH, Elkady A, Bardaweel SA, Lignos DG. Earhtuqake loss assessment of steel frame buildings desinged in highly seismic regions. Proceedings of 5th ECCOMAS Thematic Conference on Computational Methods in Structural Dynamics and Earthquake Engineering (COMPDYN 2015), Crete Island, Greece, May 25-27, 2015; $1496-1512$.

24. Hwang SH, Elkady A, Lignos DG. Design decision support for steel frame buildings through an earthquake-induced loss assessment. Proceedings of 2nd Conference on Improving the Seismic Performance of Existing Buildings and Other Structures, San Francisco, CA, December 10-12, 2015; 340-352, DOI:10.1061/9780784479728.028. 
25. FEMA. State of the art report on systems performance of steel moment frames subject to earthquake ground shaking. Report No. FEMA-355C, Federal Emergency Management Agency, Washington, DC 2000.

26. Foutch DA, Yun SY. Modeling of steel moment frames for seismic loads. Journal of Constructional Steel Research 2002; 58(5-8):529-564, DOI:10.1016/S0143-974X(01)00078-5.

27. Ji X, Kato M, Wang T, Hitaka T, Nakashima M. Effect of gravity columns on mitigation of drift concentration for braced frames. Journal of Constructional Steel Research 2009; 65(12):2148-2156, DOI:10.1016/j.jcsr.2009.07.003.

28. Flores FX, Charney FA, Lopez-Garcia D. Influence of the gravity framing system on the collapse performance of special steel moment frames. Journal of Constructional Steel Research 2014; 101:351-362, DOI:10.1016/j.jcsr. 2014.05.020.

29. Elkady A, Lignos DG. Effect of gravity framing on the overstrength and collapse capacity of steel frame buildings with perimeter special moment frames. Earthquake Engineering \& Structural Dynamics 2015; 44(8):1289-1307, DOI:10.1002/eqe.2519.

30. Ruiz-García J, Miranda E. Residual displacement ratios for assessment of existing structures. Earthquake Engineering \& Structural Dynamics 2006; 35(3):315-336, DOI:10.1002/eqe.523.

31. Ruiz-García J, Chora C. Evaluation of approximate methods to estimate residual drift demands in steel framed buildings. Earthquake Engineering \& Structural Dynamics 2015; 44(15):2837-2854, DOI:10.1002/eqe.2611.

32. Elkady A, Lignos DG. Effect of composite action on the dynamic stability of special steel moment resisting frames designed in seismic regions. Proceedings of ASCE Structures Congress 2013, Pittsburgh, PA, May 2-4, 2013; 2151-2160, DOI:10.1061/9780784412848.188.

33. Baradaran Shoraka M, Yang TY, Elwood KJ. Seismic loss estimation of non-ductile reinforced concrete buildings. Earthquake Engineering \& Structural Dynamics 2013; 42(2):297-310, DOI:10.1002/eqe.2213.

34. AISC. Prequalified connections for special and intermediate steel moment frames for seismic applications. ANSI/AISC 358-10. American Institute of Steel Construction: Chicago, IL, 2010.

35. ASCE. Minimum design loads for buildings and other structures. ASCE/SEI 7-10. American Society of Civil Engineers: Reston, VA, 2010.

36. Goulet CA, Haselton CB, Mitrani-Reiser J, Beck JL, Deierlein GG, Porter KA, Stewart JP. Evaluation of the seismic performance of a code-conforming reinforced-concrete frame building-from seismic hazard to collapse safety and economic losses. Earthquake Engineering \& Structural Dynamics 2007; 36(13):1973-1997, DOI:10.1002/eqe.694.

37. AISC. Specification for structural steel buildings. ANSI/AISC 360-10. American Institute of Steel Construction: Chicago, IL, 2010.

38. Eads L, Miranda E, Krawinkler H, Lignos DG. An efficient method for estimating the collapse risk of structures in seismic regions. Earthquake Engineering \& Structural Dynamics 2013; 42(1):25-41, DOI:10.1002/eqe.2191.

39. Mitrani-Reiser J. An ounce of prevention: probabilistic loss estimation for performance-based earthquake engineering. PhD Thesis, California Institute of Technology, Pasadena, CA 2007.

40. Lignos DG, Kolios D, Miranda E. Fragility assessment of reduced beam section moment connections. Journal of Structural Engineering 2010; 136(9):1140-1150, DOI:10.1061/(ASCE)ST.1943-541X.0000214.

41. McKenna FT. Object oriented finite element programming frameworks for analysis, algorithms and parallel computings. PhD Thesis, University of California at Berkeley, Berkeley, CA 1997.

42. Lignos DG, Hikino T, Matsuoka Y, Nakashima M. Collapse assessment of steel moment frames based on EDefense full-scale shake table collapse tests. Journal of Structural Engineering 2013; 139(1):120-132, DOI: 10.1061/(ASCE)ST.1943-541X.0000608.

43. Ibarra LF, Medina RA, Krawinkler H. Hysteretic models that incorporate strength and stiffness deterioration. Earthquake Engineering \& Structural Dynamics 2005; 34(12):1489-1511, DOI:10.1002/eqe.495.

44. Lignos DG, Krawinkler H. Deterioration modeling of steel components in support of collapse prediction of steel moment frames under earthquake loading. Journal of Structural Engineering 2011; 137(11):1291-1302, DOI: 10.1061/(ASCE)ST.1943-541X.0000376.

45. Zhang X, Ricles JM. Experimental evaluation of reduced beam section connections to deep columns. Journal of Structural Engineering 2006; 132(3):346-357, DOI:10.1061/(ASCE)0733-9445(2006)132:3(346).

46. Liu J, Astaneh-Asl A. Cyclic testing of simple connections including effects of slab. Journal of Structural Engineering 2000; 126(1):32-39, DOI:10.1061/(ASCE)0733-9445(2000)126:1(32).

47. Zareian F, Medina RA. A practical method for proper modeling of structural damping in inelastic plane structural systems. Computers \& Structures 2010; 88(1-2):45-53, DOI:10.1016/j.compstruc.2009.08.001.

48. FEMA. Quantification of building seismic performance factors. Report No. FEMA-P695, Federal Emergency Management Agency, Washington, DC 2009.

49. Ibarra LF, Krawinkler H. Global collapse of frame structures under seismic excitationss. Blume Center Technical Report No. 152, The John A. Blume Earthquake Engineering Center, Stanford University, Stanford, CA. 2005.

50. Lignos DG, Krawinkler H, Whittaker AS. Prediction and validation of sidesway collapse of two scale models of a 4-story steel moment frame. Earthquake Engineering \& Structural Dynamics 2011; 40(7):807-825, DOI: 10.1002/eqe.1061.

51. Lignos DG, Krawinkler H. Sidesway collapse of deteriorating structural systems under seismic excitations. Blume Center Technical Report No. 177, The John A. Blume Earthquake Engineering Center, Stanford University, Stanford, CA. 2012.

52. Vamvatsikos D, Cornell CA. Incremental dynamic analysis. Earthquake Engineering \& Structural Dynamics 2002; 31(3):491-514, DOI:10.1002/eqe.141.

53. Luco N, Bazzurro P. Does amplitude scaling of ground motion records result in biased nonlinear structural drift responses? Earthquake Engineering \& Structural Dynamics 2007; 36(13):1813-1835, DOI:10.1002/eqe.695.

54. Haselton CB, Baker JW, Liel AB, Deierlein GG. Accounting for ground-motion spectral shape characteristics in structural collapse assessment through an adjustment for epsilon. Journal of Structural Engineering 2011; 137(3):332-344, DOI:10.1061/(ASCE)ST.1943-541X.0000103.

55. Baird A, Tasligedik AS, Palermo A, Pampanin S. Seismic performance of vertical nonstructural components in the 22 February 2011 Christchurch earthquake. Earthquake Spectra 2014; 30(1):401-425, DOI:10.1193/ 
031013EQS067M.

56. Mahin SA. Lessons from damage to steel buildings during the Northridge earthquake. Engineering Structures 1998; 20(4-6):261-270, DOI:10.1016/S0141-0296(97)00032-1.

57. Miranda E, Mosqueda G, Retamales R, Pekcan G. Performance of nonstructural components during the 27 February 2010 Chile earthquake. Earthquake Spectra 2012; 28(S1):S453-S471, DOI:10.1193/1.4000032.

58. Adam C, Ibarra LF, Krawinkler H. Evaluation of P-Delta effects in non-deteriorating MDOF structures from equivalent SDOF systems. Proceedings of the 13th World Conference on Earthquake Engineering (13WCEE), Vancouver, Canada, August 1-6, 2004; Paper No. 3407.

59. Roeder CW. State of the art report on connection performance. Report No. FEMA-355D, Federal Emergency Management Agency, Washington, DC 2000. 